\title{
Post-zygotic sterility and cytonuclear compatibility limits in S. cerevisiae xenomitochondrial cybrids
}

\author{
Mário Špírek ${ }^{\dagger \neq}$, Silvia Polákovát ${ }^{\dagger}$ Katarína Jatzová and Pavol Sulo *\#
}

Department of Biochemistry, Faculty of Natural Sciences, Comenius University, Bratislava, Slovakia

Edited by:

Anton Vila-Sanjurjo, Brown

University, USA

Reviewed by:

Gonzalo M. Gajardo, Universidad de

Los Lagos, Chile

Margarida Matos, Universidade de

Lisboa, Portugal

*Correspondence:

Pavol Sulo, Department of

Biochemistry, Faculty of Natural

Sciences, Comenius University,

Mlynská Dolina, 84215 Bratislava,

Slovakia

e-mail: sulo@fns.uniba.sk

${ }^{t}$ Present address:

Mário Špírek, International Clinical Research Center, St. Anne's

University Hospital, Brno, Czech; Silvia Poláková, Max F. Perutz

Laboratories, University of Vienna, Vienna, Austria

FThe authors wish it to be known that, in their opinion, the first author and corresponding author should be regarded as a joint First Authors.
Nucleo-mitochondrial interactions, particularly those determining the primary divergence of biological species, can be studied by means of xenomitochondrial cybrids, which are cells where the original mitochondria are substituted by their counterparts from related species. Saccharomyces cerevisiae cybrids are prepared simply by the mating of the $\rho^{0}$ strain with impaired karyogamy and germinating spores from other Saccharomyces species and fall into three categories. Cybrids with compatible mitochondrial DNA (mtDNA) from Saccharomyces paradoxus CBS 432 and Saccharomyces cariocanus CBS 7994 are metabolically and genetically similar to cybrids containing mtDNA from various $S$. cerevisiae. Cybrids with mtDNA from other $S$. paradoxus strains, $S$. cariocanus, Saccharomyces kudriavzevii, and Saccharomyces mikatae require a period of adaptation to establish efficient oxidative phosphorylation. They exhibit a temperature-sensitive phenotype, slower growth rate on a non-fermentable carbon source and a long lag phase after the shift from glucose. Their decreased respiration capacity and reduced cytochrome aa3 content is associated with the inefficient splicing of $\operatorname{cox} 113 \beta$, the intron found in all Saccharomyces species but not in $S$. cerevisiae. The splicing defect is compensated in cybrids by nuclear gain-of-function and can be alternatively suppressed by overexpression of MRP13 gene for mitochondrial ribosomal protein or the MRS2, MRS3, and MRS4 genes involved in intron splicing. S. cerevisiae with Saccharomyces bayanus mtDNA is unable to respire and the growth on ethanol-glycerol can be restored only after mating to some mit ${ }^{-}$strains. The nucleo-mitochondrial compatibility limit of $S$. cerevisiae and other Saccharomyces was set between S. kudriavzevii and $S$. bayanus at the divergence from S. cerevisiae about 15 MYA. The MRS1-cox1 S. cerevisiae/S. paradoxus cytonuclear Dobzhansky-Muller pair has a neglible impact on the separation of species since its imperfection is compensated for by gain-of-function mutation.

Keywords: cytonuclear incompatibility, xenomitochondrial cybrids, Saccharomyces yeasts, adaptation, Dobzhansky-Muller pairs, speciation

\section{INTRODUCTION}

Understanding the genetic basis of speciation is one of the major tasks in evolutionary biology. In spite of the recent methodological progress, many questions still remain unanswered or debated (Nosil and Schluter, 2011; Butlin et al., 2012). In general several types of reproductive isolation have been considered, but most genetic studies are focused on the speciation process derived from interspecific hybrids. Consequently, the cause of the inviability and sterility resulting from the post-zygotic barrier has been studied (Dobzhansky, 1937; for a review see Butlin et al., 2012). Yeasts, particularly Saccharomyces cerevisiae, are the experimental model of choice for such speciation studies due to their ability to mate with related species and their homothallism, allowing the mating type switch in haploid cells after almost every division. Therefore, interspecies hybrids between different Saccharomyces species are able to establish fertile lines of "a new species" after repeated cycles of sporulation and self-fertilization (Greig et al., 2002; reviewed in Greig, 2009; Chou and Leu, 2010; Louis, 2011; Morales and Dujon, 2012). In Saccharomyces yeasts, the reproductive barrier is post-zygotic and this can be attributed to non-collinear chromosomes' (Delneri et al., 2003; Charron et al., 2014; Hou et al., 2014) "anti-recombination" resulting from the action of a "confused" mismatch repair system (Hunter et al., 1996; for a review see Greig, 2009; Louis, 2011).

In general, the divergence of species results from responses to negative epistatic genetic interactions, known as "DobzhanskyMuller incompatibilities," which are alleles that are completely normal in their native genetic background but are deleterious on the genetic background of the other population. The hypothesis was confirmed experimentally and reduced efficiency of meiotic reproduction was observed in hybrids made from populations adapted to two divergent environments (Dettman et al., 2007) and later some genes responsible for the divergence were identified (Anderson et al., 2010). So far, no Dobzhansky-Muller nuclear incompatibilities have been found in yeasts (Greig, 2007; Kao et al., 2010), but they have been reported between mitochondrial and nuclear genes (reviewed in Lee et al., 2008; Chou and Leu, 2010; Chou et al., 2010). 
Functional mitochondria are indispensable for yeast sporulation, which is the essential step in hybrid speciation. The fate of mitochondrial DNA (mtDNA) has been largely overlooked in hybrid speciation lines, but it is believed that progeny inherit a complete mitochondrial $(\mathrm{mt})$ genome from one of the yeast species, as has been described in natural or in vitro created hybrids (Marinoni et al., 1999; Rainieri et al., 2008; Solieri et al., 2008). Mitochondria have a limited genome, and efficient oxidative phosphorylation requires co-adaptation of mitochondrial and nuclear genes, despite divergent paces of evolution. Their biogenesis depends on the tender interplay of up to thousand proteins encoded by the nucleus, with eight proteins and several dozen gene products encoded by Saccharomyces mtDNA (for a review see Lipinski et al., 2010; Schmidt et al., 2010; Fox, 2012). Consequently, in interspecific hybrids the mitochondrial genome from one partner does not have to communicate equally well with the nuclear genome of the second partner and the progeny can be sterile or non-viable. Such nucleo-mitochondrial communication has been reported as a determinant of reproductive isolation during yeast evolution (Lee et al., 2008; Chou et al., 2010; reviewed in Chou and Leu, 2010; Solieri, 2010). Pairs of genes with interspecific incompatibility were found using nonrespiring chimeras containing mitochondria from one partner as well as a set of original chromosomes, where one or two were replaced with their counterpart from second partner (Lee et al., 2008; Chou et al., 2010). Then, the elements of interspecific nucleo-mitochondrial incompatibility can be recovered from genomic DNA libraries according to the ability to rescue the respiratory defect. This approach has revealed several DobzhanskyMuller pairs: (i) Saccharomyces bayanus nuclear AEP2 allele with S. cerevisiae/Saccharomyces paradoxus mitochondrial atp 9 gene; (ii) $S$. cerevisiae MRS1 nuclear gene required for the splicing of some mitochondrial group I introns with $S$. paradoxus/S. bayanus mtDNA likely some in coxl genes; and (iii) $S$. cerevisiae/S. paradoxus AIM22 gene variants coding enzyme required for the addition of lipoate to some mitochondrial proteins imported from cytoplasm with $S$. bayanus mitochondria (Chou et al., 2010). In spite of providing valuable data, this approach failed in the preparation of an entire set of chimeras with single chromosome replacement implicating additional Dobzhansky-Muller pairs (Lee et al., 2008; Chou et al., 2010).

Dobzhansky-Muller cytonuclear incompatibilities can generally be directly studied by the transplacement of mitochondria from one species to mutants lacking mitochondrial DNA $\left(\rho^{0}\right)$ from a second species, according to the restoration of the ability to respire and grow on a non-fermentable carbon source. In early studies mitochondria from unrelated yeast species were introduced to S. cerevisiae (Yoshida, 1979; Sakanaka et al., 1996; Osusky et al., 1997). However, these experiments could not be reproduced (Špírek et al., 2000) and most of them should be considered experimental artifacts, mainly as consequence of the absence of mtDNA analysis in cybrids and unreliable taxonomy, as most of the "unusual" compatible yeasts were misclassified (Barnett, 1992; Špírek et al., 2000; Vaughan-Martini and Martini, 2011; Sulo, unpublished results). Currently, the Saccharomyces genus consists of the species S. cerevisiae, S. paradoxus, Saccharomyces mikatae, Saccharomyces kudriavzevii, S. arboricolus, S. bayanus var. bayanus, S. bayanus var. uvarum, and Saccharomyces pastorianus (Vaughan-Martini and Martini, 2011). However, whole genome analysis has shown that the last three species are cold-adapted alloploids of S. cerevisiae and the newly described species Saccharomyces eubayanus (reviewed in Hittinger, 2013). In addition, Saccharomyces cariocanus is considered to be more a $S$. paradoxus variant as this species is reproductively isolated from $S$. paradoxus by four translocations but not by sequence (Liti et al., 2006; reviewed in Hittinger, 2013). Consequently the successful re-establishment of mitochondrial functions in $S$. cerevisiae $\rho^{0}$ strains has been achieved by the transplacement of isolated mitochondria or protoplast fusion only from yeasts currently classified as synonymous to $S$. cerevisiae (Osusky et al., 1997; Špírek et al., 2000) or the most closely-related species S. paradoxus (Špírek et al., 2000). However, in this case the rate of the re-established respiration was only partial (Špírek et al., 2000). In the opposite direction, S. cerevisiae mtDNA was able to restore respiration in S. paradoxus mitochondria to a level close to the original (Sulo et al., 2003), indicating the unidirectional character of these nucleo-mitochondrial incompatibilities (Sulo et al., 2003), a phenomenon that has been confirmed in interspecific hybrids with different combinations of nuclear and mitochondrial genomes (Chou et al., 2010).

Thus, xenomitochondrial cybrids are a valuable tool in the study of nucleo-mitochondrial interactions, particularly those determining the primary divergence of biological species. In this work we elaborated a simple procedure for the preparation of xenomitochondrial cybrids with the aim to report nucleomitochondrial incompatibilities associated with an inability to splice an unusual mitochondrial intron $\operatorname{cox} 1 \mathrm{I} 3 \beta$ and the capability of cells to compensate for the splicing defect after the adaptation period by the gain-of-function of nuclear genes.

\section{MATERIALS AND METHODS YEAST STRAINS}

The Saccharomyces species used for the transfer of mitochondria to S. cerevisiae were as follows: S. cerevisiae NRRL Y-12632 ${ }^{T}$ (CBS 1171), S. paradoxus NRRL Y-17217 ${ }^{T}$ (CBS 432), S. paradoxus (CBS 2908), S. kudriavzevii NRRL Y-27339 ${ }^{T}$ (CBS 8840), S. cariocanus NRRL Y-27337 ${ }^{T}$ (CBS 7994), S. mikatae NRRL Y-27341 ${ }^{T}$ (CBS 8839), S. bayanus var. uvarum NRRL Y-17034 ${ }^{T}$ (CBS 395), S. bayanus var. bayanus NRRL Y-12624 ${ }^{T}$ (CBS 380), and S. pastorianus (CBS 1504, CBS 1513), which were obtained from J. Piškur Lund University. The following abbreviations apply: CBS corresponds to the Culture Collection of the Centraalbureau voor Schimmelcultures and Fungal Biodiversity Center, Utrecht, The Netherlands; NRRL to the Agricultural Research Service Culture Collection, US Department of Agriculture, Peoria, Illinois, USA; and NCYC to the National Collection of Yeast Cultures, Institute of Food Research, Norwich, United Kingdom. The superscript $T$ in yeast designations indicates type of strains (Vaughan-Martini and Martini, 2011). The other S. cerevisiae wild type strains used in this study are as follows: CCY 21-37-2 (CBS 457), CCY 2146-1 (CBS 4054), CCY 21-37-1 (CBS 1426), CCY 21-45-1 (CBS 1782), CCY 21-8-1 (CBS 436), CCY 21-4-11 (CBS 1460), CCY 2111-1 (formerly Saccharomyces chevalieri, CBS 400), CCY 21-10-1 (CBS 435), CCY 21-36-1, CCY 21-42-1 (formerly Saccharomyces 
capensis, CBS 2247), CCY 21-33-3 (formerly Saccharomyces italicus, CBS 2909), CCY 21-21-1 (formerly Saccharomyces oviformis, CBS 429), CCY 21-14-1, CCY 21-1-1 (CBS 382), CCY 21-4-27 (CBS 1200), CCY 21-15-6 (CBS 439), and CCY 21-15-1 (CBS 381 ), which were obtained from the Culture Collection of Yeasts (CCY; the former Czechoslovak Collection of Yeasts), located at the Institute of Chemistry, Slovak Academy of Sciences, in Bratislava. The proper taxonomic classification of any strain used in this study has been confirmed by the sequencing of the D1/D2 region from a large ribosomal RNA subunit and mitochondrial cox2 and rns genes, as described in Kurtzman (2003). S. paradoxus (synonymous to Saccharomyces douglasii) CBS 7400 strain was kindly provided by $\mathrm{H}$. Fukuhara, Institute Curie, Orsay. The laboratory acceptor strains of mitochondria MCC109 $\rho^{0}(M A T$ $\alpha$, ade2-1, ura3-52, kar1-1, $\left.\rho^{0}\right)$; mit $^{-}$testers PTY6 (MAT $\alpha$, ade2, ura3-52, kar1-1, cox2-17), K2145 (MATa, ade2, lys, kar1-1, cox2-

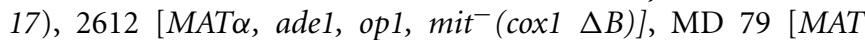
a, leu1, kar1-1 (cox1-delB)], akar170 [MATa, his ${ }^{-}$, lys ${ }^{-}$, kar1-1,

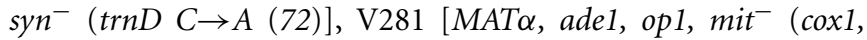
aI1 $T \rightarrow A(1856)], \alpha$ OP1/M1301 [MAT $\alpha$, op1, ura3-1, leu2-3, 112, his3-11,15, trp1-289, mit $^{-}$(cob bI1M1301)], as well as derivatives of W303 1A (MATa, ade2-1, trp1-1, leu2-3, 112, his3-11,15, ura3-1, can1-100, Gal ${ }^{+}, \mathrm{psi}^{+}, \mathrm{\rho}^{+}$), DBY 747 (MATa, trp1-289, leu2-3, 112, his3-1, ura3-52, $\mathrm{Gal}^{-}, \rho^{+}$), and DBY 747/M1301 [MATa, trp1-289, leu2-3, 112, his3-1, ura3-52, Gal ${ }^{-}$, mit $^{-}$(cob bI1M1301)] have been described by Špírek et al. (2000, 2002) and Sulo et al. (2003). Other mit ${ }^{-}$strains 5B [MATa, ade1 ${ }^{-}, l y s 1^{-}$, mit $^{-}$(cox1 ailai2 junction)], and $\mathrm{AD} 1$ [MATa, ade1 ${ }^{-}$, lys $1^{-}$, mit $^{-}$ (cox1 ailai2 junction)] are described in detail in Anziano et al. (1990).

\section{Media}

Yeasts were routinely cultivated on YPD (1\% bactopeptone, 1\% yeast extract, $2 \%$ glucose), YPGE (1\% bactopeptone, $1 \%$ yeast extract, $3 \%$ glycerol, $2 \%$ ethanol), minimal medium $(0.67 \%$ YNB, $2 \%$ glucose), and sporulation media $(0.1 \%$ yeast extract, $1 \%$ potassium acetate, $0.05 \%$ glucose).

\section{Transplacement of mitochondria by interspecific cytoduction}

Sporulated diploid collection yeasts $\left(10^{8}-10^{9} / 50 \mu \mathrm{l}\right)$ were treated with Zymolyase $20 \mathrm{~T} 0.5 \mathrm{mg} / \mathrm{ml}$. After 10-20 minutes (when the majority of spores were released), the spores were vortexed for $30 \mathrm{~s}$ and washed with distilled water mixed with a twofold amount of fresh MCC109 $\rho^{0}$ cells, and the suspension was applied in a small volume $(10-50 \mu \mathrm{l})$ on YPD plates. After one day's incubation the mating efficiency was controlled microscopically and aliquots of $10^{8}$ cells were streaked onto selection FOA plates $(3 \%$ glycerol, $2 \%$ ethanol, $0.5 \%$ glucose, $0.67 \%$ YNB, $20 \mathrm{mg} / \mathrm{l}$ adenine, $50 \mathrm{mg} / \mathrm{l}$ uracil, $2 \%$ agar, with $1 \mathrm{~g} / \mathrm{l}$ of 5 -fluoroorotic acid AUDFOA) for the selection of respiring cybrids (2\% glucose, $0.67 \% \mathrm{YNB}, 20 \mathrm{mg} / \mathrm{l}$ adenine, $50 \mathrm{mg} / \mathrm{l}$ uracil, $2 \%$ agar, with $1 \mathrm{~g} / \mathrm{l}$ of 5-fluoroorotic acid AUFOA) to select any cybrids. The plates were incubated at $28^{\circ} \mathrm{C}$ and after 5-7 days they were scraped and resuspended in demineralized water and spotted in tenfold dilutions onto YPD plates. After 3 days of cultivation the number of colonies grown from single drops were counted and plated in corresponding dilutions on AUFOA or YPD plates. Single colonies were then screened for correct auxotrophic markers and the ability to grow on YPGE plates. The presence of mtDNA in colonies that did not grow on YPGE plates was determined by restriction digestion or after mating to the mit $^{-}$tester strain K2145, allowing non-adapted or non-respiring cybrids to be studied. A similar selection procedure is widely used when DNA is delivered to mitochondria by biolistics (Fox et al., 1991). The approach has a few constraints, such as the poor sporulation ability observed in a number of the collection strains. However, the problem can be bypassed by several cycles of sporulation and germination. The other expected pitfall, low mating ability, was not observed since even the less related species S. cerevisiae and S. bayanus produced an incredible amount of zygotes (Marinoni et al., 1999). Finally, the acceptor strain lacking mtDNA must carry the kar1-1 mutation, because their substitution by regular $\rho^{0}$ strains does not yield cybrids but hybrids.

\section{DNA analysis}

The presence of mtDNA in cybrids was screened by the Hinf I restriction digestion of genomic DNA isolated according to the laboratory modification of Philippsen et al. (1991). Mitochondrial DNA was isolated according to Defontaine et al. (1991). Karyotypes have been determined by pulsed-field electrophoresis, as described in Marinoni et al. (1999), with minor modification. Electrophoresis was carried out at $150 \mathrm{~V}$ for $6.5 \mathrm{~h}$, with a switching time of $240 \mathrm{~s}$ followed by $8 \mathrm{~h}$ with a switching time of $160 \mathrm{~s}$, then $9 \mathrm{~h} 45$ minutes with pulse duration of $90 \mathrm{~s}$, and finally $14 \mathrm{~h} 38$ minutes with $60 \mathrm{~s}$ pulse duration.

\section{DNA amplification and sequencing}

D1D2 domain of 26S rDNA was amplified according to Kurtzman and Robnett (2003), part of the mitochondrial cox2 gene was amplified with primers cox2 357: 5'-CAG GAT CCA GCA ACA CCA AAT CAA GA and cox 2 rev: $5^{\prime}$-CAT GCC CCA TAG AAG ACA CTT TCT CT (amplification condition $94^{\circ} \mathrm{C}-3 \mathrm{~min}$, $35 \times\left(94^{\circ} \mathrm{C}-30 \mathrm{~s}, 52^{\circ} \mathrm{C}-1 \mathrm{~min}, 72^{\circ} \mathrm{C}-1 \mathrm{~min}\right), 72^{\circ} \mathrm{C}-5 \mathrm{~min}$, $14^{\circ} \mathrm{C}$ ). Part of rns gene was amplified with primers YM5: $5^{\prime}-$ AAG AAT ATG TTG GTT CAG A and YM13: 5'-ATT CTA CGG ATC CTT TAA ACC A (amplification condition $94^{\circ} \mathrm{C}-3 \mathrm{~min}$ $\left.35 \times\left(94^{\circ} \mathrm{C}-30 \mathrm{~s}, 45^{\circ} \mathrm{C}-1 \mathrm{~min}, 72^{\circ} \mathrm{C}-2 \mathrm{~min}\right), 72^{\circ} \mathrm{C}-5 \mathrm{~min}\right)$. Cox $113 \beta$ was amplified using the primers SDA2: $5^{\prime}$-AAT CTA CAC TAG GTC CTG AAT GTG CCT GAA and SDA3: 5'-AAT CAG GTG CTG GTA CAG GAT GAA (amplification condition $94^{\circ} \mathrm{C}-3 \mathrm{~min}, 35 \times\left(94^{\circ} \mathrm{C}-30 \mathrm{~s}, 45^{\circ} \mathrm{C}-1 \mathrm{~min}, 72^{\circ} \mathrm{C}-2 \mathrm{~min}\right)$, $\left.72^{\circ} \mathrm{C}-5 \mathrm{~min}\right)$. Entire cox $1 \mathrm{mtDNA}$ sequences were obtained as described in Prochazka et al. (2012) or were extracted from running the whole mtDNA sequencing project using Illumina MiSeq and paired-end $(2 \times 100 \mathrm{nt}$ technology) assembled with CLC genomics Workbench 7.0.3 (http://www.clcbio.com).

\section{RNA analysis}

RNA was isolated as described by Köhrer and Domdey (1991). Thirty micrograms was separated on $1.0 \%$ agarose-formaldehyde gels, transferred to a nylon membrane, and hybridized by the DIG High Prime DNA Labeling and Detection Kit (Roche Molecular Biochemicals) labeled probes, as described in Brown (1993). 


\section{Disruption of MRP13 gene}

The region between $\mathrm{BamHI}$ and $\mathrm{XbaI}$ restriction site of the gene was replaced with a LEU2 gene XbaI-BamHI fragment and introduced to the haploid spores of adapted and non-adapted cybrids carrying the leu2 mutation and S. paradoxus CBS 7400 mtDNA as well as to W303 $1 \mathrm{~A} \rho^{0}$ and $\rho^{+}$strains. Disruption was confirmed after Southern blotting by hybridization with MRP13 specific probe.

\section{Oxygen consumption}

Oxygen consumption was measured at $30^{\circ} \mathrm{C}$ with a Clark oxygen electrode using $2 \%$ ethanol as the substrate. Cybrid cells were grown first for $12 \mathrm{~h}$ at $28^{\circ} \mathrm{C}$ in liquid YPD medium, then pelleted by centrifugation ( $10 \mathrm{~min}, 2500 \mathrm{~g}$ ), and then cultivated an additional $12 \mathrm{~h}$ in $50 \mathrm{ml}$ YPGE media, before the measurement cells were harvested and washed twice with distilled water. Oxygen consumption was measured in $2 \mathrm{ml}$ water suspension with $2 \%$ ethanol as a substrate. Respiratory rates were expressed as consumed nmoles $\mathrm{O}_{2} / \mathrm{min}$ per $5 \times 10^{8}$ cells. The solubility of the $\mathrm{O}_{2} 237 \mathrm{nmol} / \mathrm{ml}$ water was considered and at the end of measurement oxygen consumption was inhibited by the addition of antimycine at the final concentration of $10 \mu \mathrm{g} / \mathrm{ml}$.

\section{Cytochrome spectra}

Cytochrome spectra were recorded in mitochondrial suspensions (0.4 M sorbitol, $5 \mathrm{mM}$ EDTA pH 6-8, 0.25\% BSA $8 \mathrm{mg} / \mathrm{ml}$ of proteins) by Double Wavelength Double Beam Perkin-Elmer 557 spectrophotometer, as described in Tzagoloff et al. (1975). Mitochondria were isolated according to (Sulo et al., 1989) from an overnight culture grown on $1 \%$ bactopeptone, $1 \%$ yeast extract, and $2 \%$ galactose. Difference spectra were recorded at room temperature in suspensions split in half, where one was oxidized by hydrogen peroxide (final concentration $50 \mathrm{mM}$ ) and the other was reduced by the addition of dithionite (a few crystals).

\section{Growth curves}

Fresh yeasts grown overnight on the plates were inoculated into liquid YPGE. At $24 \mathrm{~h}$ intervals the aliquots were withdrawn diluted to the density of $\leq 0.4$ at $600 \mathrm{~nm}$.

\section{Preparation of $\rho^{-}$mutants}

$\rho$ mutations in intronless strain DBY 747 were induced by ethidium bromide, as described in Fox et al. (1991). Mutants carrying the segments of the $\operatorname{cox} 1$ gene were identified according to the ability to complement it $^{-}$mutation in coxl but not mit $^{-}$ mutations in other genes ( $c o b, \operatorname{trn} D, \operatorname{cox} 2)$.

Yeasts were transformed according to Soni et al. (1993). Other procedures were done as described in the manuals of Ausubel et al. (2002) and Guthrie and Fink (1991).

\section{RESULTS}

\section{THE ABILITY TO POPULATE S. CEREVISIAE WITH MITOCHONDRIA FROM RELATED SPECIES-PHYLOGENETIC LIMIT}

To elucidate the limit of nucleo-mitochondrial compatibility among Saccharomyces, we made an attempt to construct xenomitochondrial cybrids containing nuclei from S. cerevisiae and mtDNA from all other Saccharomyces species. To avoid any misinterpretations resulting from incorrect taxonomic classification, the origin of any strain used in this study has been verified by the sequencing of the D1/D2 region from the large ribosomal RNA subunit and mitochondrial cox 2 and $r n s$ genes, as described in Kurtzman (2003). The collection consisted of about 20 S. cerevisiae, three $S$. paradoxus strains, of which two were involved in a previous study (Špírek et al., 2000), and three relatively new but quite well-characterized species: $S$. cariocanus, $S$. kudriavzevii, and S. mikatae (Naumov et al., 2000) and S. bayanus.

Instead of protoplast fusion (Špírek et al., 2000) the mitochondria were transferred by mating the spores from different Saccharomyces species to ade2-1, ura3-52, kar1-1, $\rho^{0} S$. cerevisiae strain, since the karl-1 mutation in the acceptor strain significantly reduces the karyogamy events (Fox et al., 1991). Cybrids regaining efficient mitochondrial functions can be simply selected as the mostly red/pink colonies on the plates containing 5-fluoroorotic acid (FOA) and an excess of non-fermentable carbon source. FOA is lethal for any yeast carrying the wild type URA3 gene (Sikorski and Boeke, 1991), and therefore it inhibits the growth of "true hybrids" and all wild type Saccharomyces strains (Figure 1). Cybrids with various degrees of re-established mitochondrial functions can be also obtained on synthetic selection plates with FOA and glucose as a carbon source, as they can preferentially survive 5-7 days incubation (Figure 1B). After plating to a single colony, cybrids from donor species can be distinguished according to their auxotrophy.

The presence and origin of mitochondrial genomes can be unambiguously assigned according to restriction fragment polymorphisms that have long been used for molecular "typing" of different strain-to-strain variations in yeasts (e.g., Querol et al., 1992; Špírek et al., 2000). Consequently HinfI or EcoRV restriction profiles of all the cybrids chosen for further study were identical to the mtDNA profiles from parent species, which excludes the rearrangement of DNA (Figures 2A-C). The authenticity of transferred $\mathrm{mt}$ genomes was confirmed also by whole genome sequencing. The very rare event of single chromosome transfer is known if FOA selection pressure is applied (Nilsson-Tillgren et al., 1980), and this could possibly be responsible for compatibility. Cybrid karyotypes were not distinguishable from the original respiration deficient $S$. cerevisiae strain but variable enough to distinguish hybrids with both genomes and some of single chromosome transfers (Figure 2D; Marinoni et al., 1999). The uniform karyotype excludes the heterokaroyn variants and the transmission of intact nuclei from the mitochondrial donors. Auxotrophic phenotypes and mating type were well-preserved in all examined cybrids.

\section{THE RE-ESTABLISHMENT OF NUCLEO-MITOCHONDRIAL COMPATIBILITY WITH FOREIGN mtDNA IN S. CEREVISIAE OFTEN ACCOMPANIES THE ADAPTATION PROCESS}

Cybrids with partially re-established mitochondrial functions can be obtained on selection media containing glucose. If cells from a single cybrid colony are transferred from selection media (with glucose) on the plates with a non-fermentable carbon source such as glycerol and ethanol (YPGE), unambiguously good growth is displayed only in cybrids containing mitochondrial genome from various $S$. cerevisiae strains, the $S$. paradoxus strain CBS 432, and the S. cariocanus strain CBS 7994 (Figure 3, Table 1). Other cybrids gave rise to a mixed population that consisted mainly of poorly growing colonies. However, most of these cybrids with 
A
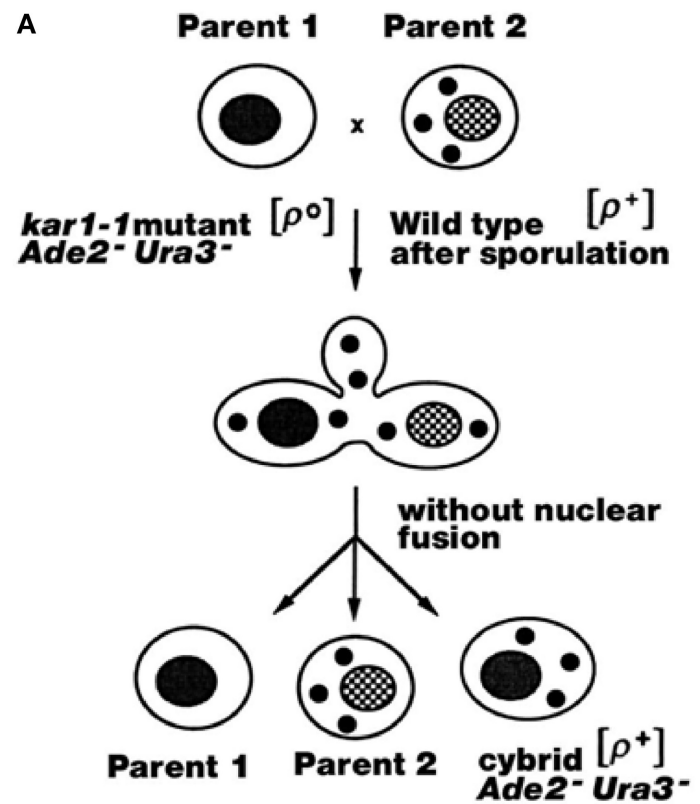

B

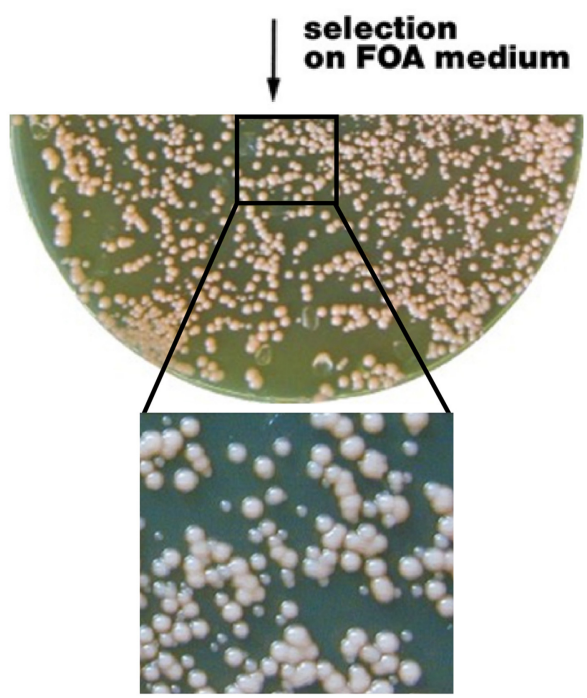

FIGURE 1 | Construction of xenomitochondrial cybrids. (A) General selection chart. (B) Plating of cytoduction mixture (MCC109 $\rho^{0} \times$ S. kudriavzevii CBS 8840) after 5 days cultivation on selection medium with FOA on YPD plate. Detail: smaller white colonies - non-adapted cybrids; larger pink colonies - adapted cybrids.

mtDNA from S. paradoxus CBS 7400, S. paradoxus CBS 2908, and S. mikatae CBS 8839 were capable of forming colonies on non-fermentable substrate after prolonged incubation on YPGE (Figure 3, Table 1), indicating an adaptation process. Cybrids with mt genome S. kudriavzevii CBS 8840 growing on glycerol also appeared, with a shorter but significant delay. Even after 2 months of incubation we did not observe any colony growing on glycerol among the cybrids containing mtDNA from the less-related yeasts of the S. bayanus - uvarum group.

To understand the nature of the adaptation process, we transferred the cytoplasm from adapted cybrids capable of growing on
YPGE again by cytoduction to a different S. cerevisiae W303 1A $\rho^{0}$ strain (carrying YEp352 plasmid with URA3 selection marker) in a ratio of 100:1. Putative cytoductant colonies were selected on glucose plates lacking uracil, and the presence of mtDNA was determined by DAPI staining. Colonies with W303 1A auxotrophic markers containing mtDNA were then transferred onto rich YPGE plates, and their growing ability was examined (Table 1). Again, the ability to utilize a non-fermentable carbon source in these second generation cybrids mimicked the behavior of cybrids obtained by first transfer from parental non-cerevisiae species. In spite of the reduced adaptation period, the proportionality confirms that transfer of nuclear genes from original parental species is not required.

Reduced spore viability, used in taxonomic classification, is a very profound feature of interspecific yeast hybrids as well the landmark of nucleo-mitochondrial Dobzhansky-Muller incompatibility (Naumov et al., 2000; Chou and Leu, 2010). Therefore, $S$. cerevisiae cybrids repopulated with foreign mtDNA and capable of growing on a non-fermentable carbon source (adapted) were crossed with the $S$. cerevisiae W303 1A $\rho^{0}$ strain carrying the YEp352 plasmid. Diploids were selected on the minimal media supplemented with adenine, and their sporulation ability was examined. All diploids could sporulate and the majority of spores (from 70 to $90 \%$ ) germinated, suggesting the absence of Dobzhansky-Muller incompatibility pairs. In addition, spores from asci were separated by micromanipulator and full tetrads were tested for auxotrophic requirements and the ability to grow on YPGE. The segregation of the ability to grow on glycerolethanol when the mating partner was cybrid harboring mtDNA from S. paradoxus CBS 432, S. cariocanus CBS 7994, or any $S$. cerevisiae was at a ratio of 4:0, which emphasizes the direct compatibility of mitochondrial and nuclear genomes from different species. However, if one of the mating partners was a cybrid with mtDNA from $S$. paradoxus CBS 2908, S. paradoxus CBS 7400, S. mikatae CBS 8839, or S. cariocanus CBS 7994, the ability to grow on glycerol and ethanol segregated at a 2:2 ratio (Figure 4), indicating a single gene gain-of-function, responsible for the adaptation phenomenon. In the case of cybrids with S. kudriavzevii CBS $8840 \mathrm{mtDNA}$, the ratio was unexpectedly 3:1, although a small number of tetrads segregated at a ratio of $2: 2$ or 4:0, suggesting most likely the gain-of-function in two different genes involved in the adaptation process. The authenticity of the tetrads was always confirmed by the segregation of nuclear markers.

\section{EFFECTIVENESS OF OXIDATIVE PHOSPHORYLATION IN THE XENOMITOCHONDRIAL CYBRIDS}

The performance of oxidative phosphorylation was assessed according to the rate of oxygen consumption, measured in cultures grown in liquid YPD medium followed by a $12 \mathrm{~h}$ cultivation in YPGE, which allows non-adapted variants to be compared as well. The respiration capacity of cybrids that display good nucleo-mitochondrial compatibility (compatible $\mathrm{mt}$ genomes) from the $S$. paradoxus strain CBS 432 and S. cariocanus CBS 7994 decreased to $40 \%$ of the S. cerevisiae (Table 2). The oxygen consumption was reduced to $20-30 \%$ in adapted cybrids with mtDNA from S. kudriavzevii, S. paradoxus CBS 7400, S. paradoxus 


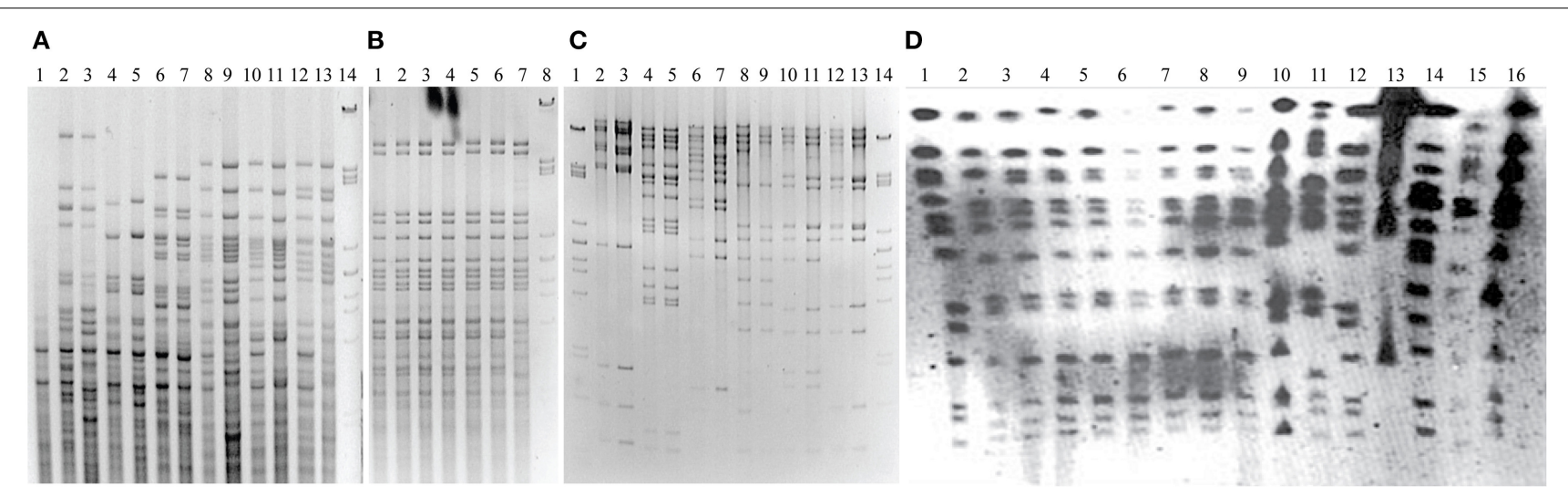

FIGURE 2 | Origin of mitochondrial and nuclear genomes in cybrids. (A) Hinfl digest of genomic DNA separated on 1\% agarose gel. Lanes:

S. cerevisiae MCC109 $\rho^{0}$ (acceptor strain) (1); S. kudriavzevii CBS 8840 cybrid (2) parent (3); S. mikatae CBS 8839 cybrid (4) parent (5); S. cariocanus CBS 7994 cybrid (6) parent (7); S. paradoxus CBS 2908 cybrid (8) parent (9); S. paradoxus CBS 7400 cybrid (10) parent (11); S. paradoxus CBS 432 cybrid (12) parent (13); size standard $\lambda /$ Pstl (14). (B) Hinfl digest of genomic DNA separated on $1 \%$ agarose gel. Lanes: $S$. bayanus CBS 380 cybrids (1-6) parent (7); size standard $\lambda / P s t$ (8). (C) EcoRV digest of mtDNA separated on $1 \%$ agarose gel. Lanes: size standard $\lambda /$ Pstl $(1,14) ;$ S. kudriavzevii CBS 8840 cybrid (2) parent (3); S. mikatae CBS 8839 cybrid (4) parent (5); S. cariocanus
CBS 7994 cybrid (6) parent (7); S. paradoxus CBS 2908 cybrid (8) parent (9); S. paradoxus CBS 7400 cybrid (10) parent (11); S. paradoxus CBS 432 cybrid (12) parent (13); size standard $\lambda /$ Pstl (14). (D) Pulse-field electrophoresis of cybrids (1-8) and parental species (9-16): Lanes 1-9 S. cerevisiae cybrids with mt genomes from S. bayanus CBS 380 (1); S. mikatae CBS 8839 (2); S. paradoxus CBS 7400 (3); S. paradoxus CBS 2908 (4); S. kudriavzevii CBS 8840 (5); S. cariocanus CBS 7994 (6); S. paradoxus CBS 432 (7); S. cerevisiae strain W303 1A (8); MCC109 $\rho^{0}$ parental strain (9); S. paradoxus CBS 432 (10); S. cariocanus CBS 7994 (11); S. paradoxus CBS 2908 (12); S. kudriavzevii CBS 8840 (13); S. mikatae CBS 8839 (14) S. bayanus CBS 380 (15); S. cerevisiae strain W303 1A (16).
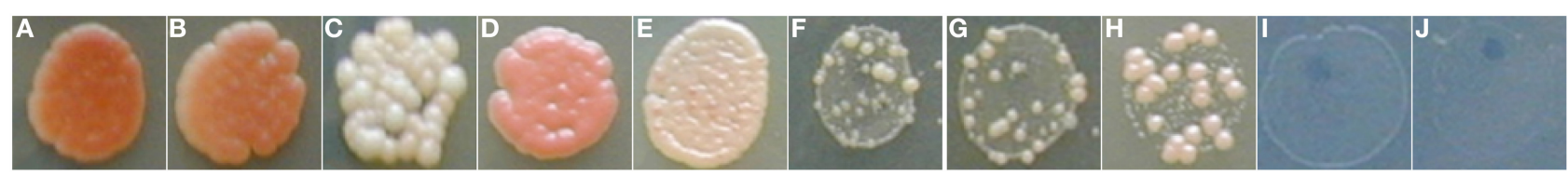

FIGURE 3 | Adaptation of cybrids. Cells from single cybrid colony were diluted, spotted on the plates with the non-fermentable carbon source (YPGE) and cultivated for 7 days at $28^{\circ} \mathrm{C}$. S. cerevisiae cybrids with mtDNA from: (A) S. cerevisiae W303 1A; (B) S. cerevisiae CBS 400;
(C) S. paradoxus CBS 432; (D) S. cariocanus CBS 7994; (E) S. kudriavzevii CBS 8840; (F) S. paradoxus CBS 2908; (G) S. paradoxus CBS 7400; (H) S. mikatae CBS 8839; (I) S. bayanus CBS 380; (J) S. cerevisiae MCC109 $\rho^{0}$.
CBS 2908, and S. mikatae CBS 8839. A threshold respiration rate about $2-10 \%$ of the wild type can be detected in non-adaptated variants but not in a cybrid with $S$. bayanus mtDNA.

The growth rate on the medium with non-fermentable carbon is widely used as a good criterion for assessing the phenotype of various mitochondrial mutations. Figure 5A shows that cybrids with mitochondria from the $S$. paradoxus strain CBS 432 and S. cariocanus CBS 7994 grow nearly at the same rate as cybrids with $S$. cerevisiae mitochondria. Cybrids requiring an adaptation period (S. paradoxus CBS 7400, S. paradoxus CBS 2908, S. mikatae CBS 8839) exhibit a significantly slower growth rate. Besides the slower growth rate, they exhibit an extremely long lag phase (3-8 days) if they are transferred from glucose to glycerol (Figure 5B).

\section{ADAPTATION INTRODUCES TEMPERATURE SENSITIVE PHENOTYPE ON GLUCOSE}

To shed more light on the scale of the communication ability of xenomitochondrial cybrids, we examined their ability to grow at an elevated temperature. While cybrids with $\mathrm{mtDNA}$ from $S$. cerevisiae and compatible Saccharomyces strains (S. paradoxus CBS 432 and S. cariocanus CBS 7994) were capable of growing at $37^{\circ} \mathrm{C}$, even on non-fermentable carbon sources, other cybrids with noncerevisiae mtDNA were not. Surprisingly, they were not capable of growing at an elevated temperature even on YPD with glucose as a carbon source, while the parental S. cerevisiae $\rho^{0}$ mutant was. Their growth was abolished even after the transfer from 37 to $30^{\circ} \mathrm{C}$, indicating the lethal effect of elevated temperature (Figure 6).

\section{MITOCHONDRIAL COX1 GENE IS THE MAIN DETERMINANT OF XENONUCLEO-MITOCHONDRIAL COMPATIBILITY}

The segment of mtDNA responsible for interspecific incompatibility can be determined by petite mapping (Fox et al., 1991). Therefore, we first crossed all non-adapted cybrids with $S$. cerevisiae mit $^{-}$strains carrying mutations in single mitochondrial genes $\operatorname{cox} 1, \operatorname{trn} D, \operatorname{cob}$, and $\operatorname{cox} 2$ (details listed in the section Materials and Methods). All combinations grew well on YPGE plates, but not diploids from the crosses of three different cox 1 mutants (carrying deletion of exon2 AD1, 5B or $8.2 \mathrm{~kb}$ deletion of exon2-intron I5 $\beta$ MD 79) suggested an impaired compatibility associated with the coxl gene (Figure 7). This outcome was confirmed by petite mapping using $\rho^{-}$mutants 
prepared from the $S$. cerevisiae DBY 747 strain harboring intronless mtDNA (Seraphin et al., 1987). All $\rho^{-}$strains able to complement the growth defects of non-adapted cybrids carried mtDNA fragments containing the entire coxl gene, which was confirmed by genetic and physical mapping.

A defect in the large subunit of the coxl gene confirmed cytochrome spectra of reduced vs. oxidized mitochondrial extracts (Tzagoloff et al., 1975). The ratio of cytochromes $c c 1-b$ aa3 similar to the wild type is maintained in S. cerevisiae cybrids, with $S$. cariocanus and S. paradoxus CBS 432 mtDNA. In other cybrids with only partially compatible genomes, a cytochrome $a a 3$ peak is barely detectable in non-adapted forms and reaches about $50 \%$ of the wild level after adaptation. In S. cerevisiae with $S$. bayanus mtDNA the cytochrome aa3 signal is missing.

Table 1 | Re-established growth on non-fermentable carbon source (YPGE).

\begin{tabular}{|c|c|c|c|}
\hline $\begin{array}{l}\text { S. cerevisiae cybrids } \\
\left(\text { MCC109 } \rho^{0} \text { ) with }\right. \\
\text { mitochondrial genome } \\
\text { from: }\end{array}$ & $\begin{array}{c}\text { Proportion of } \\
\text { colonies } \\
\text { growing } \\
\text { immediately } \\
\text { on YPGE in } \\
(\%)^{b}\end{array}$ & $\begin{array}{c}\text { A period } \\
\text { required for } \\
\text { re-established } \\
\text { growth on } \\
\text { YPGE in (days) }\end{array}$ & $\begin{array}{l}\text { A period } \\
\text { required for } \\
\text { re-established } \\
\text { growth on } \\
\text { YPGE in (days) } \\
\text { after second } \\
\text { cytoduction to } \\
\text { W303 1A strain }\end{array}$ \\
\hline S. cerevisae W303 1A & 100 & 0 & 0 \\
\hline S. cerevisae CBS $400^{\circ}$ & 100 & 0 & 0 \\
\hline S. paradoxus CBS 432 & 100 & 0 & 0 \\
\hline S. paradoxus CBS 2908 & 2 & $6-14$ & 4 \\
\hline S. paradoxus CBS 7400 & 2 & $6-14$ & 4 \\
\hline S. kudriavzevii CBS 8840 & 50 & $1-3$ & 1 \\
\hline S. mikatae CBS 8839 & 15 & $6-14$ & 4 \\
\hline S. cariocanus CBS 7994 & 100 & 0 & 0 \\
\hline S. bayanus CBS 380 & 0 & $>60$ & - \\
\hline S. cerevisae MCC109 $\rho^{0}$ & 0 & $>60$ & - \\
\hline
\end{tabular}

a The same was observed for other S. cerevisiae wild type strains listed in the Section Material and Methods and any examined respiring laboratory strain.

b Up to 50 colonies were examined.

${ }^{c}$ As visible colonies that arose from patch.

${ }^{d}$ Mitochondria transferred from primary cybrids to the strain W303 $1 \mathrm{~A} \rho^{0}$ transformed with the plasmid YEp352 by kar cross.
It appears that the defect in cox 1 expression is a major drawback in the interspecific nucleo-mitochondrial (in)compatibility in Saccharomyces (Figure 8).

\section{THE ABILITY OF cox1-I3 $\beta$ INTRON TO SPLICE IN A NEW ENVIRONMENT IS THE MAIN DETERMINANT OF XENONUCLEO-MITOCHONDRIAL COMPATIBILITY}

The inability of the cox 1 -I3 $\beta$ intron to splice in a new environment has been already suspected to be the main obstacle to $S$. cerevisiae/S. paradoxus interspecific nucleo-mitochondrial communication (Kotylak et al., 1985; Tian et al., 1993) due to the divergence of the Mrs1p splicing factor (Herbert et al., 1992; Chou et al., 2010). Therefore, we amplified the region of the insertion in all species involved in our study. Cox 1 -I3 $\beta$ in different sizes was found in any non-cerevisiae Saccharomyces, but never in the 20 examined Saccharomyces strains isolated from different geographical regions (not shown). In order to understand its role in the adaptation process, whole-cell RNA from adapted cybrids was analyzed by Northern blot. Hybridization with the probe specific to the first two $S$. cerevisiae cox 1 exons revealed two different bands in which one was linked to spliced coxl

Table 2 | Respiration capacity of cybrids.

\begin{tabular}{|c|c|c|c|c|}
\hline \multirow[t]{2}{*}{$\begin{array}{l}\text { S. cerevisiae cybrids } \\
\left(\text { MCC109 } \rho^{0}\right) \text { with } \\
\text { mitochondrial genome } \\
\text { from: }\end{array}$} & \multicolumn{2}{|c|}{$\begin{array}{c}\text { Respiration capacity } \\
\text { (nmol } \\
\mathrm{O}_{2} / \mathrm{min} / 5 \times 10^{8} \\
\text { cells) }\end{array}$} & \multicolumn{2}{|c|}{$\begin{array}{c}\text { Relative } \\
\text { respiration } \\
\text { capacity (\%) }\end{array}$} \\
\hline & A & NA & A & NA \\
\hline S. cerevisiae W303 1A & $190 \pm 50$ & - & 100 & - \\
\hline S. cerevisiae CBS 400 & 180 & - & 95 & - \\
\hline S. paradoxus CBS 432 & 80 & - & 42 & - \\
\hline S. cariocanus CBS 7994 & 77 & - & 41 & - \\
\hline S. kudriavzevii CBS 8840 & 64.6 & 33 & 34 & 17 \\
\hline S. paradoxus CBS 7400 & 43.7 & 3.88 & 23 & 2 \\
\hline S. paradoxus CBS 2908 & 55 & 3.81 & 29 & 2 \\
\hline S. mikatae CBS 8839 & 64 & 4 & 34 & 2 \\
\hline S. bayanus CBS 380 & - & 0 & - & 0 \\
\hline S. cerevisiae MCC109 $\rho^{0}$ & - & 0 & - & 0 \\
\hline
\end{tabular}

$A$, adapted; $N A$, non-adapted.

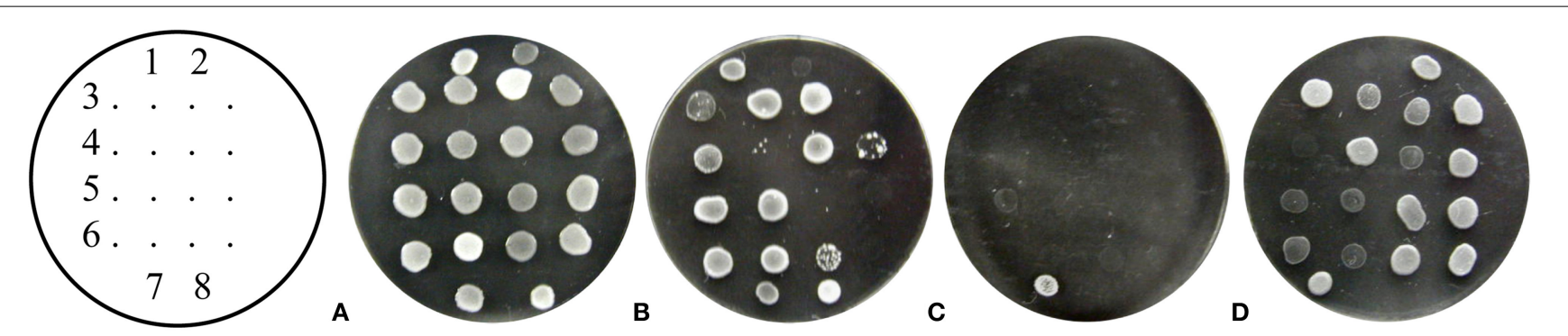

FIGURE 4 | Adaptive gain-of-mutation is linked to nuclear gene. Zygotes from mating of adapted cybrids with S. paradoxus CBS 7400 mtDNA and W303 1A/YEp352 $\rho^{0}$ strain were sporulated and tetrads dissected. Colonies from individual spores were spotted on different media. (3-6) Four individual tetrads; Controls: (1) MCC109 $\rho^{0}$; (2) cybrid with S. paradoxus CBS 7400 mtDNA; (7) W303 1A $\rho^{+}$; (8) W303 1A $\rho^{0}$. Plates (A) YPD $30^{\circ} \mathrm{C}$; (B) YPD $37^{\circ} \mathrm{C}$; (C) YPGE $37^{\circ} \mathrm{C}$; (D) $\mathrm{YPGE} 30^{\circ} \mathrm{C}$. Cultivated 3 days at $28^{\circ} \mathrm{C}$. 


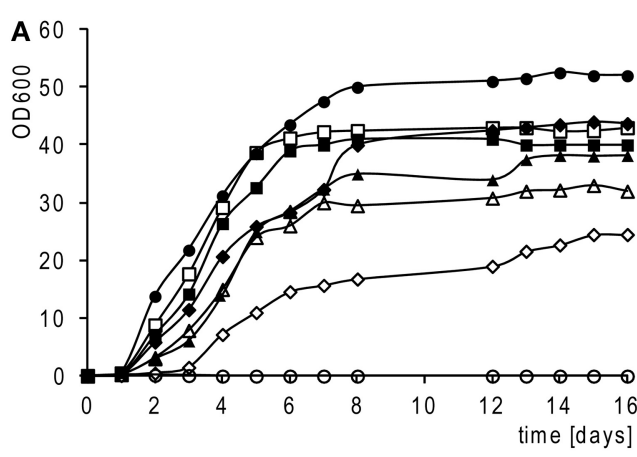

FIGURE 5 | Growth rates of adapted cybrids. Cells grown in liquid complete medium with glycerol and ethanol (YPGE). (A) Inoculum from YPGE; (B) inoculum from YPD; S. cerevisiae cybrids (strain MCC109 $\rho^{0}$ ) with $\mathrm{mt}$ genomes from: S. cerevisiae strain W303 1A (•); S. bayanus

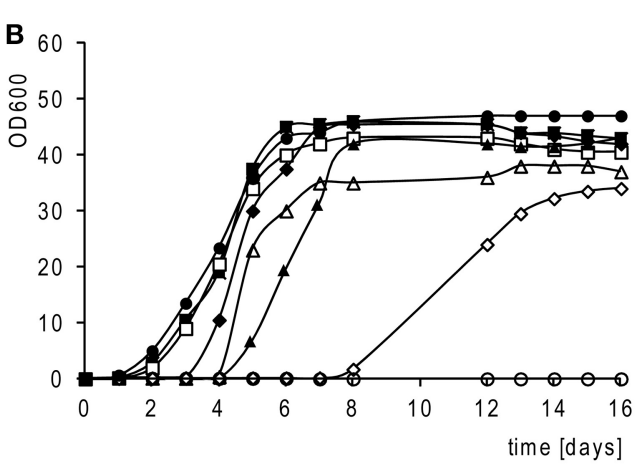

CBS 380 (o); S. paradoxus CBS 432 (ロ); S. cariocanus CBS $7994(\square)$; S. paradoxus CBS $7400(\mathbf{\Lambda})$; S. paradoxus CBS 7400; $(\Delta)$; S. kudriavzevii (CBS 8840) (\$); S. mikatae CBS $8839(\diamond) ; 10 D 600$ unit equals $6 \times 10^{7}$ cells $/ \mathrm{ml}$.
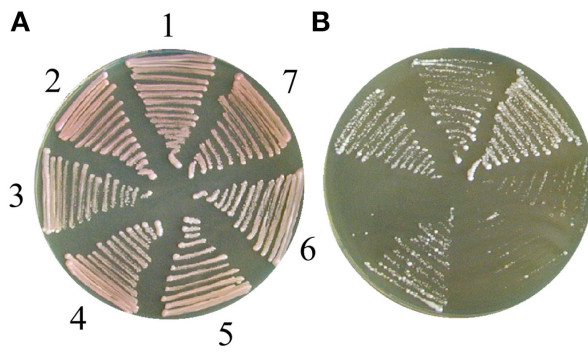

FIGURE 6 | Temperature sensitive growth of xenomitochondrial cybrids. Cultivation (A) YPD $30^{\circ} \mathrm{C}$, (B) YPD $37^{\circ} \mathrm{C}$ (C) YPGE $30^{\circ} \mathrm{C}$ (D) YPGE $37^{\circ} \mathrm{C}$ : $S$. cerevisiae cybrids with mitochondrial genomes from $S$. cerevisiae strain

\section{C}
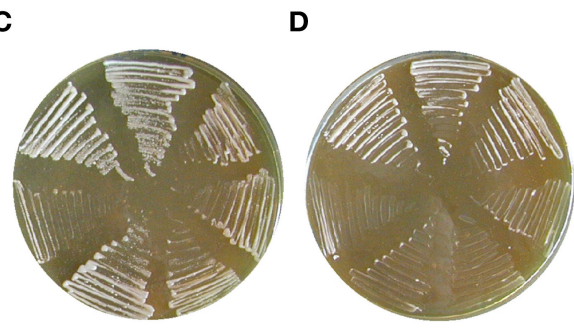

W303 1A (1); S. paradoxus CBS 432 (2); S. paradoxus CBS 2908 (3); S. kudriavzevii CBS 8840 (4); S. mikatae CBS 8839 (5); S. paradoxus CBS 7400 (6); S. cariocanus CBS 7994 (7).
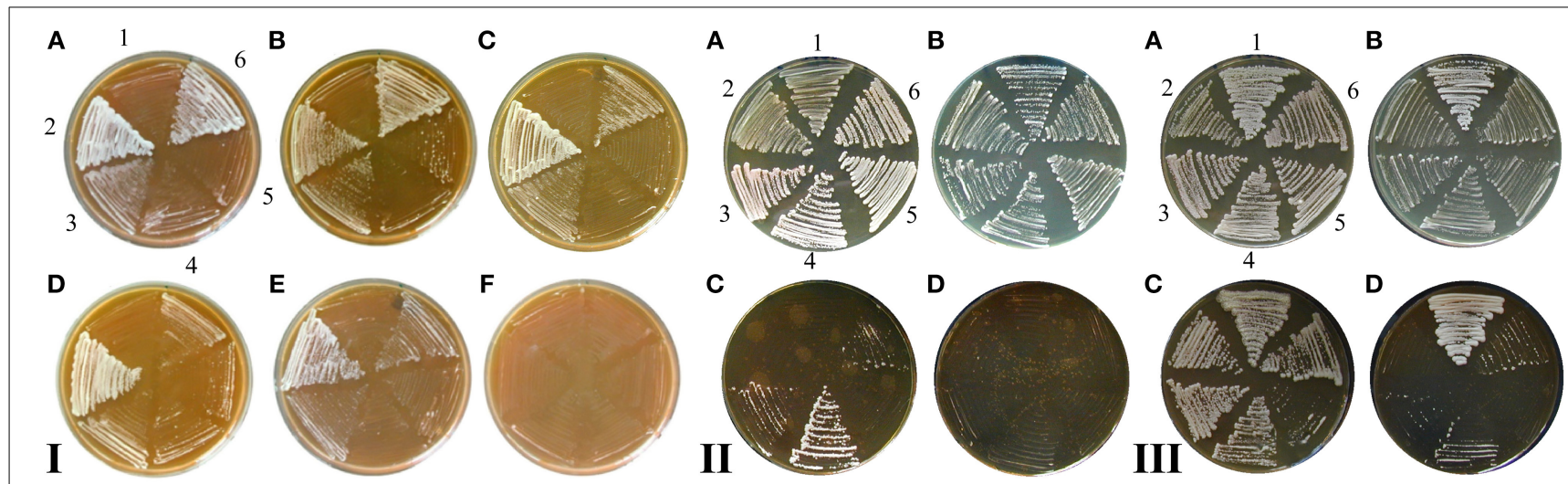

FIGURE $7 \mid \operatorname{Cox} 1$ gene as the main determinant of

xenonucleo-mitochondrial (in)compatibility. (I) Growth of non-adapted

S. cerevisiae cybrids with mitochondrial genomes from S. paradoxus CBS 7400 (A); S. paradoxus CBS 2908 (B); S. mikatae CBS 8839 (C); S. kudriavzevii CBS 8840 (D); S. bayanus CBS 380 (E); MCC109 $\rho^{0}$ Strain (negative control) (F); after mating to different mit ${ }^{-}$strains: (1) MD79 (mit ${ }^{-}$in cox1), (2) akar170 (mit $^{-}$in trnAsp), (3) M1301 (mit ${ }^{-}$in cob), (4) AD1 (mit in cox1); (5) 5B (mit in cox1); (6) K2145 (mit in cox2). Cultivated on YPGE plates for 4 days at $30^{\circ} \mathrm{C}$. Growth of non-adapted cybrids after the mating with $S$. cerevisiae DBY $747 \rho^{0}$ (II) and S. cerevisiae DBY $747 \rho^{-}$containing intronless cox1 gene (III) mit ${ }^{-}$ strain 2612 (positive control) (1); S. cerevisiae cybrids with mitochondrial genomes from: S. paradoxus CBS 7400 (2); S. paradoxus CBS 2908 (3); S. kudriavzevii CBS 8840 (4); S. mikatae CBS 8839 (5); S. paradoxus CBS 7400 (6). Plates (A) YPD $30^{\circ} \mathrm{C}$, (B) YPD $37^{\circ} \mathrm{C}$, (C) YPGE $30^{\circ} \mathrm{C}$, (D) YPGE $37^{\circ} \mathrm{C}$. Cultivation 4 days. 


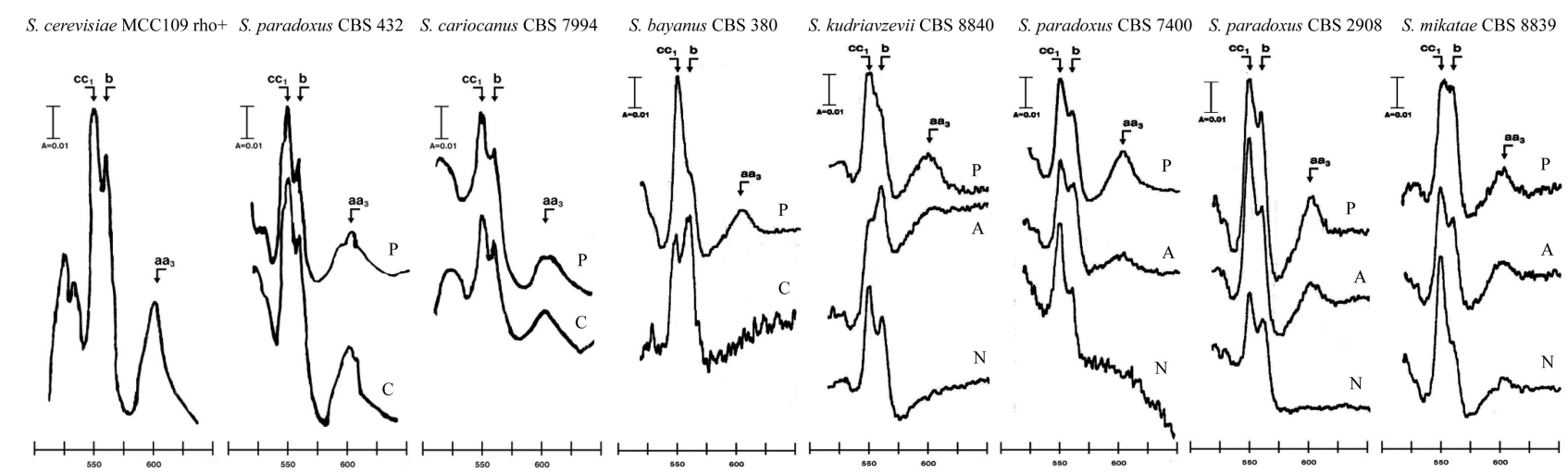

FIGURE 8 | Cytochrome spectra of parental species and xenomitochondrial cybrids. Absorption maxima for cytochrome aa 3 - 603 nm; cytochrome b-560 nm; cytochrome cc1-550 nm. Abbreviations: P, parent; C, cybrid; A, adapted cybrid; N, non-adapted cybrid.

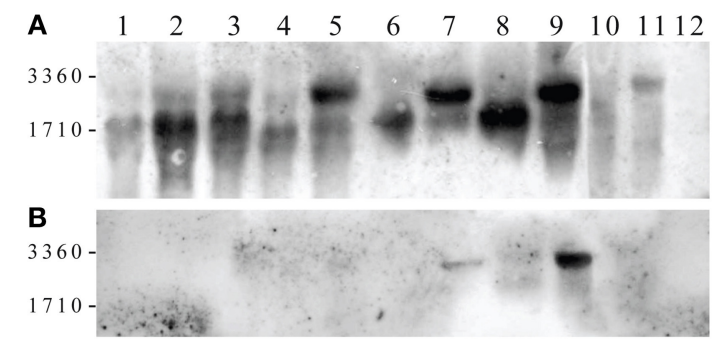

FIGURE 9 | Northern blot of RNA from parental species and adapted cybrids. RNA separated on agarose-formaldehyde gel, transferred on nylon membrane was hybridized with the probe specific to first two exons from S. cerevisiae cox1 gene. (A) Lanes: S. cerevisiae (W303 1A $\rho^{+}$) (1); S. paradoxus CBS 432 parent (2), cybrid (3); S. kudriavzevii CBS 8840 parent (4), cybrid (5); S. paradoxus CBS 2908 parent (6), cybrid (7); S. paradoxus CBS 7400 parent (8), cybrid (9), S. mikatae CBS 8839 parent (10), cybrid (11); S. cerevisiae MCC109 $\rho^{0}$ (12). (B) The same membrane stripped and hybridized with probe specific to $13 \beta$ from $S$. paradoxus CBS 7400. Markers: 3360 nt 26S rRNA; 1710 nt 18S rRNA.

mRNA about $1700 \mathrm{nt}$ long, and the second was linked to longer mRNA $2500 \mathrm{nt}$ in size, corresponding to the cox 1 premRNA with unspliced I $3 \beta$ intron RNA (Figure 9A). The signal intensity of longer form was very profound in cybrids, but was noticeable in parental strains only after overexposure. The membrane was stripped and hybridized with a probe specific to I3 $\beta$ from $S$. paradoxus CBS 7400 (Figure 9B). In this case, the probe hybridized only to the longer cox 1 mRNA, providing evidence that it contains an unspliced I $3 \beta$ intervening sequence. Apparently, the lower levels of aa3 cytochromes are associated with a lower level of cox 1 mRNA. The effect is strain specific, because in the cybrid with $S$. paradoxus CBS $432 \mathrm{mtDNA}$, the I3 $\beta$ splicing efficiency is the same as in the parental strain (Figure 9A).

\section{SPLICING DEFECT CAN BE SUPPRESSED BY VARIETY OF NUCLEAR FACTORS (XENOADJUSTORS)}

Non-adapted cybrids provide a unique opportunity to screen for other fine Dobzhansky-Muller incompatibility pairs. Therefore, the $S$. cerevisiae strain carrying mtDNA from $S$. paradoxus CBS
7400 was transformed with two different libraries (centromeric in pYES plasmid with inserts cloned under the Gal promoter, Ramer et al., 1992; multicopy in pFL plasmid, Rose and Broach, 1991). About 40,000 colonies from both libraries were replica-plated on YPGE plates and those with plasmid-dependent YPGE growth were selected. From the low copy pYES library we obtained 13 clones, all with the insert of the MRP13 (mitochondrial ribosomal protein) gene involved in mitochondrial protein synthesis (Partaledis and Mason, 1988) inserted in both directions. In the case of the multicopy pFL library, two clones carried the MRS3 and 3 the MRS4 (mitochondrial RNA splicing factors) gene belonging to the group of unspecific mitochondrial splicing factors (Wiesenberger et al., 1991). Therefore, we also examined the other family member MRS2 on multicopy plasmid that supported the growth on YPGE plates. All four genes were universally capable of suppressing the glycerol growth defect in any of the non-adapted xenomitochondrial cybrids, except those containing $S$. bayanus mtDNA. However, all these "adjustors" were active only at $28^{\circ} \mathrm{C}$ but not at $37^{\circ} \mathrm{C}$ (Figure 10). The role of MRS genes is obvious as they have been isolated as suppressors of mitochondrial splicing mutants (Koll et al., 1987). While MRS genes on multicopy plasmids introduced into the DBY 747/M1301 strain, carrying a mutation in the first intron of $c o b$ gene ( cob bI1M1301), were able to suppress the glycerol growth defect, MRP13 was not (not shown). Apparently, the suppressor effect of this gene is associated with a different process. To shed light on the role of MRP13 we disrupted the gene in an adapted cybrid with mtDNA from S. paradoxus CBS 7400 as well as in S. cerevisiae parental strain W303 1A. While MRP13 disruption in the W303 1A S. cerevisiae laboratory strain did not exhibit any apparent phenotype, the adapted variant of xenomitochondrial cybrid lost the ability to grow on glycerol, suggesting the role of this gene in the natural adaptation process. When this strain was crossed with W303 1B $\rho^{0}$, the ability to grow on glycerol was segregated at a 0:4 ratio, which confirms the role of this gene. After prolonged growth for 7-14 days by all patches with the disrupted MRP13 gene on YPGE, isolated colonies appeared that indicated the ability of cells to substitute for the knocking out of MRP13. Apparently, the impaired interspecific nucleo-mitochondrial communication 


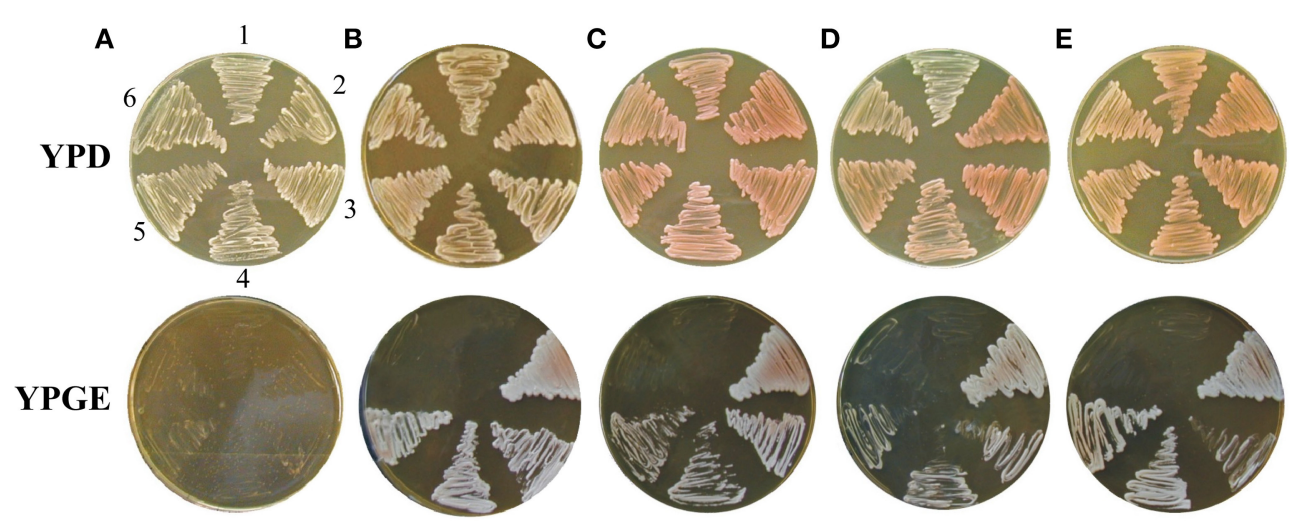

FIGURE 10 | The ability of non-adapted cybrids transformed with xenoadjustors to grow on non-fermentable carbon source.

S. cerevisiae cybrids with mitochondrial genomes from (A)

S. bayanus CBS 380 (B) S. paradoxus CBS 2908 (C) S. paradoxus
CBS 7400 (D) S. mikatae CBS 8839 (E) S. kudriavzevii CBS 8840 transformed with plasmid containing genes: 1 - none (pYES2), 2 MRP13, 3 - MRS2, 4 - MRS3, 5 - MRS4, 6 -none (YEP24). Cultivation 4 days. can be compensated for by gain of function that involves multiple genes.

\section{DISCUSSION}

$S$. cerevisiae xenomitochondrial cybrids can be prepared simply by the mating of $\rho^{0}$ strains with impaired karyogamy and germinating spores of different Saccharomyces taking advantage of the ura3 mutation and fluororotic acid selection. Cytoduction allows the construction of cybrids that grow poorly if at all on a non-fermentable carbon source due to their ability to survive the prolonged incubation on solid synthetic media with FOA better.

In general, all $S$. cerevisiae xenomitochondrial cybrids fall into three categories. The first includes cybrids containing mitochondrial genome from other $S$. cerevisiae strains, and two different species $S$. paradoxus CBS 432 and S. cariocanus CBS 7994 (Table 2). Besides a decreased respiration rate, the last two cases do not exhibit any stronger phenotype. They are metabolically and genetically similar to cybrids with mitochondrial genomes from different $S$. cerevisiae strains. Their growth rate, cytochrome content, and respiration rate is slightly lower, and they also display a short lag phase extension after the shift from glucose to glycerolethanol media. Cytoduction experiments and the segregation of glycerol grown phenotype in a 4:0 ratio in tetrads after mating to S. cerevisiae $\rho^{0}$ confirmed that these two mtDNA do not require changes in any nuclear gene to re-establish usable oxidative phosphorylation. Mismatched mitochondrial and nuclear genomes from two different $S$. cerevisiae strains often result in very profound reduced fitness on non-fermentable medium (Zeyl et al., 2005; Dimitrov et al., 2009; Paliwal et al., 2014). It is difficult to decide whether minor incompatibilities in this class of compatible cybrids are due to nucleo-mitochondrial epistasis or whether some "interspecific" factor may play a role.

The second class consists of cybrids containing mtDNA from two other $S$. paradoxus strains, S. mikatae and S. kudriavzevii, which exhibit an impaired performance of oxidative phosphorylation and a poor ability to grow on non-fermentable substrate after the transplacement of mitochondria. However, long-term incubation on glycerol media that may last for several weeks initiates the growth of adapted variants. Their respiration capacity is as low as $2-3 \%$ and increases to $20-30 \%$ of wild type level due to the elevated cytochrome aa3 content resulting from improved cox 1 -I $3 \beta$ intron splicing. This period of adaptation feature has not been observed in any other well-characterized xenomitochondrial cybrids from primate or rodent cells, and it seems to be yeast specific (Dey et al., 2000; McKenzie and Trounce, 2000; Yamaoka et al., 2000; Burton et al., 2013). The capability of growing on glycerol is temperature sensitive and this gain-of-function is associated with the loss of the ability to grow at $37^{\circ} \mathrm{C}$ even on glucose, a fermentable substrate that can be utilized anaerobically. With the exception of cybrid with $S$. kudriavzevii and S. paradoxus CBS $432 \mathrm{mtDNA}$, the exposure to an elevated temperature of $37^{\circ} \mathrm{C}$ is lethal and cells do not grow after replica-plating on a fresh YPD plate. They also exhibit a slower growth rate on glycerol, and a very remarkable feature is the extremely long lag phase after the shift from glucose to glycerol-ethanol media (Figure 5B). They appear to behave like nucleo-mitochondrial communication mutants. We failed to find any similar phenotype from the literature search, but temperature sensitive mutations in general indicate defects in the protein-coding genes often essential for cell viability (Hampsey, 1997). Conditionally, lethal growth on a non-fermentable carbon source is quite frequent and has been reported as a consequence of deletion/mutation in a few genes, for example, $A B F 2$ coding for HMG-like DNA binding protein (Kao et al., 1993) and MMF1 for protein with unknown function, but present in eukaryotes and prokaryotes (Oxelmark et al., 2000); however, these mutants are capable of growing at an elevated temperature on glucose. The respiration capacity of adapted cybrids is sufficient to perform a normal yeast cell cycle. They can sporulate after mating to $S$. cerevisiae $\rho^{0}$ strains and tetrad analysis has demonstrated their ability to grow on glycerol segregated mostly at a 2:2 ratio. The most plausible explanation for this segregation is some unspecified adaptive gain-of-mutation(s). After prolonged cultivation, single colonies arose from the patches of originally non-growing spores on glycerol media, which underlines their ability to adapt under selection pressure. A similar "adaptation" phenotype has been reported for mutants lacking 
mitochondrial porin. Deletion of the gene impairs some respiratory functions and therefore the growth on non-fermentable carbon sources; however, after a lag phase porinless mutant cells adapt to growth on glycerol (Dihanich et al., 1987). Apparently, this type behavior is not exceptional if the introduction of foreign mtDNA into $S$. cerevisiae is considered as the mutation. In yeast cells, such intervention puts pressure on the organism's genome to compensate for it so that it leads to a mutation in other genes (Teng et al., 2013).

Northern blot revealed the limited ability of $\operatorname{cox} 1-\mathrm{I} 3 \beta$ to splice as the most plausible explanation of the different behavior observed in these two cybrid classes. We made much effort to obtain the clean elimination of $\operatorname{cox} 1-\mathrm{I} 3 \beta$ by cultivation of cybrids at $37^{\circ} \mathrm{C}$. This should have introduced selection pressure that resembles intron mutation, principally used in the preparation of intronless mtDNA strain (Seraphin et al., 1987). However, cox1I $3 \beta$ intronless variants were not obtained in spite the fact that two of transferred genomes carried group II introns needed for in vivo deletion of mitochondrial introns (Figure 11; Levra-Juillet et al., 1989). Also, we tried to eliminate the intron by mating with appropriate petites, but several tens of petite strains capable of complementing the glycerol growth defect harbored a much longer cox 1 segment. Cytoduction experiments showed that the splicing factor responsible for cox1-I3 $\beta$ splicing in the $S$. paradoxus strain CBS 432 and S. cariocanus CBS $7994 \mathrm{mt}$ genomes is coded by mtDNA. To find the particular gene we made a collection of petite mutants from a cybrid with S. paradoxus CBS $432 \mathrm{mtDNA}$ and crossed them with the non-adapted cybrid with mtDNA from $S$. paradoxus CBS 7400. All petite genomes capable of complementing the glycerol growth defect were mapped to the cox 1 gene. To shed more light on this puzzling difference, we sequenced coxl (and entire mtDNAs) in all non-saccharomyces species as well in cybrids used in this study (Figure 11). The divergence in the cox $1-\mathrm{I} 3 \beta$ sequence cannot by itself explain the differences in splicing efficiency among the different $S$. paradoxus strains. Sequencing revealed only minor changes in the loop in P8 (insertion of ATAATAA pos. 298 and $(C \rightarrow A)$ transition in pos. 328, out of the catalytic core of intron) between the form in $S$. paradoxus CBS 432 (does not need adaptation) and two other S. paradoxus strains (needing adaptation; Prochazka et al., 2012, Supplementary Material). The comparison of open reading frames, hypothetically coded for maturases, directed our attention toward the $\mathrm{C}$ terminus of the open reading frame inside $\operatorname{cox} 1$-I5 $\beta$, which is not fused to the upstream exon. It is nearly identical in mtDNAs of $S$. paradoxus strain CBS 432 and $S$. cariocanus CBS 7994, but interrupted by GC cluster in two strains that require an adaptation period. However, $\operatorname{cox} 1$ - I5 $\beta$ is not mobile and its splicing requires at least five different nuclei-coded splicing factors (Mrs1, Mss116, Pet54, and perhaps open reading frame coded by cob-I3; Watts et al., 2011).

We tried to identify a fast evolving nuclear gene allowing the adaptation to "foreign" mtDNAs. A remarkable (tax reminiscent)

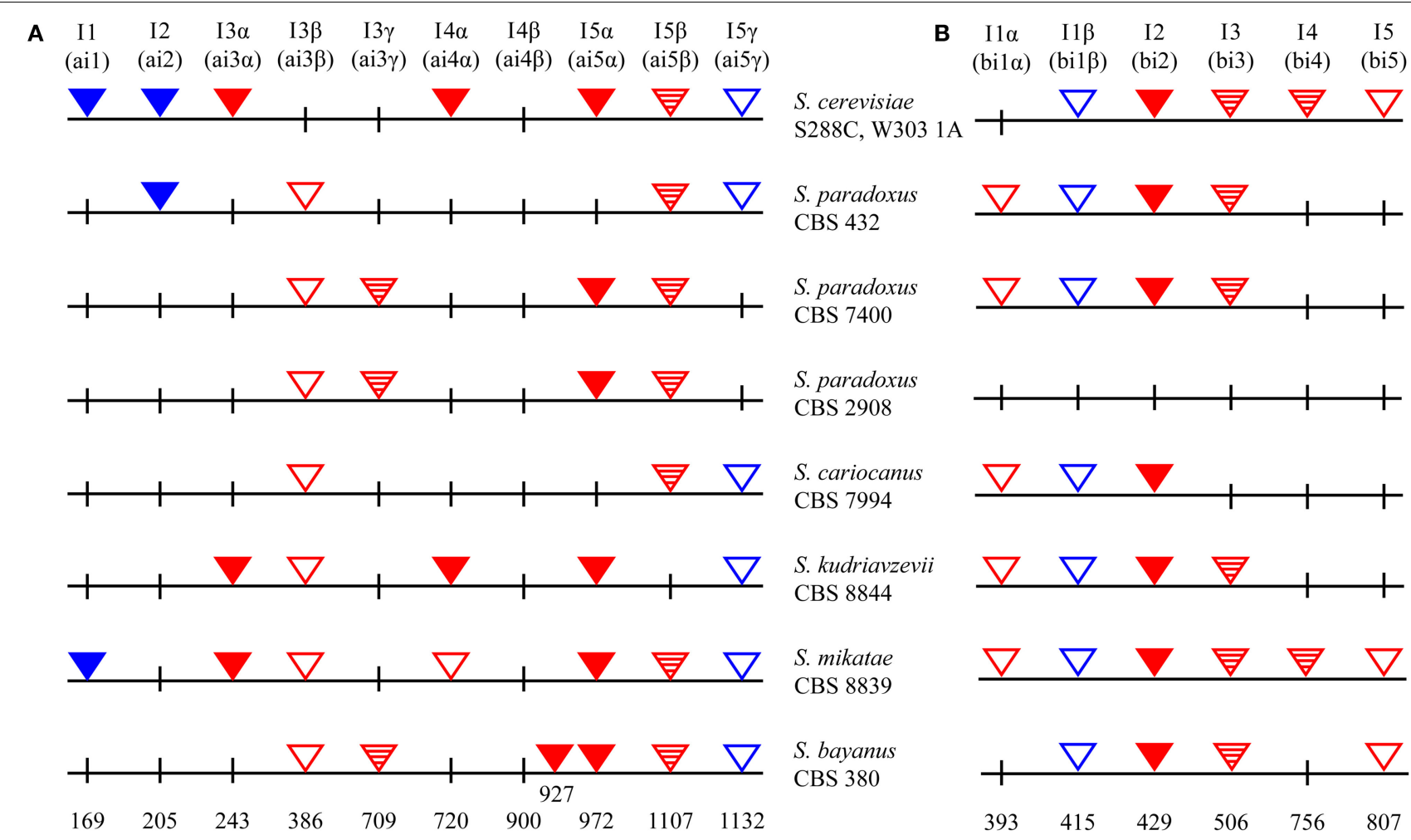

FIGURE 11 | Intron insertion sites in Saccharomyces mtDNA (A) cox1; (B) cob genes. Red - Group I introns; Blue - Group II introns; filled - with homing endonuclease (known as mobile in S. cerevisiae); checkered - with ORF (not known as mobile in S. cerevisiae); empty triangles - ORF absent. S. cerevisiae mtDNA according to Foury et al. (1998). 
feature of the adaptation process was the loss of the ability to grow on glucose at elevated temperature. The phenotype was maintained even after mtDNA elimination, and was recessive as diploids from crosses with the $S$. cerevisiae $\rho^{0}$ strain were temperature resistant. Therefore, we attempted to find a gene from low copy and multicopy libraries by selecting for the ability to grow at $37^{\circ} \mathrm{C}$, but we did not succeed, mainly due to high rate of reversion accompanied by the loss of the ability to grow well on glycerol.

When non-adapted cybrid with mtDNA S. paradoxus CBS 7400 was transformed with libraries and glycerol growing colonies, selected MRS2, MRS3, MRS4 genes were identified as multicopy suppressors. All these genes were originally isolated as suppressors of a mutation in the first introns of $c o b$ and $c o x 1$ genes in S. cerevisiae impaired in splicing (Koll et al., 1987; Waldherr et al., 1993). All MRSs code for mitochondrial transport proteins (reviewed by Arco and Satrústegui, 2005). Mrs2p was identified as a $\mathrm{Mg}^{2+}$ carrier (Kolisek et al., 2003) and another two carriers, Mrs3p and Mrs4p, were shown to be involved in iron transport (Foury and Roganti, 2002; Mühlenhoff et al., 2003). Apparently, none of these genes is responsible for adaptation. Overexpression of the MRS3 and MRS4 causes temperature-dependent growth on glycerol but not on glucose, and the disruption of these genes affected neither the mitochondrial functions nor cellular viability (Wiesenberger et al., 1991). Strains with MRS2 disruption are unable to grow on non-fermentable substrates (Wiesenberger et al., 1992). None of the MRS genes induce a temperature sensitive phenotype on glucose in non-adapted cybrids when overexpressed. MRP13 belongs to different class of xenoadjustors. Like $M R S$ genes, it is involved in ion trafficking (Eide et al., 2005), but it has been originally reported as a $35 \mathrm{kDa}$ protein participating in mitochondrial protein synthesis as a structural component of the mitochondrial ribosome (Partaledis and Mason, 1988). It may be involved in premRNA intron splicing (Pandit et al.,
2009), but it is one of the most regulated proteins, dependent on the state of the mitochondria. Like CIT2, the level of the $M R P 13$ transcript is elevated twice in $\rho^{0}$ cells (Traven et al., 2001). Despite high levels of the MRP13 transcripts, protein did not accumulate, suggesting that the protein is relatively unstable in the absence of ribosome assembly. In $\rho^{+}$cells, transcript levels were repressed several fold when on glucose compared to a non-fermentable carbon source (Partaledis and Mason, 1988). In contrast to MRS genes, MRP13 on low copy plasmid is unable to facilitate the splicing of mitochondrial intron mutants and therefore it should affect the cox 1 expression in a different way. It is a much better candidate for a natural adaptation gene because its disruption/deletion abolishes the ability to grow on glycerol in xenomitochondrial cybrids, but not in cells containing aboriginal S. cerevisiae mtDNA. However, its overexpression does not trigger the temperature sensitive phenotype on glucose.

The third class is the $S$. cerevisiae cybrid with mtDNA from S. bayanus CBS 380, which is unable to re-establish growth on the non-fermentable carbon source even after 60 days on YPGE plates. This cybrid does not respire and glycerol growth can be restored only after mating with mit $^{-}$, which does not have a defect in the cox 1 gene. Respiring xenomitochondrial cybrids with $S$. cerevisiae mtDNA in S. bayanus cannot be prepared either (Sulo et al., 2003). This establishes the nucleo-mitochondrial compatibility limit of S. cerevisiae and other Saccharomyces species between S. kudriavzevii and S. bayanus (Figure 12). The numbers concerning the divergence of particular Saccharomyces species are still being developed. However, multiple calculations have estimated that $S$. paradoxus and S. cerevisiae diverged more than 7-10 million years ago and $S$. cerevisiae, $S$. bayanus more than 20 million years ago (www.genetics.wustl.edu/saccharomycesgenomes; Lin et al., 2006; Scannell et al., 2011). The S. paradoxus/S. cerevisiae rate of divergences compared with mammals (Dujon, 2006)

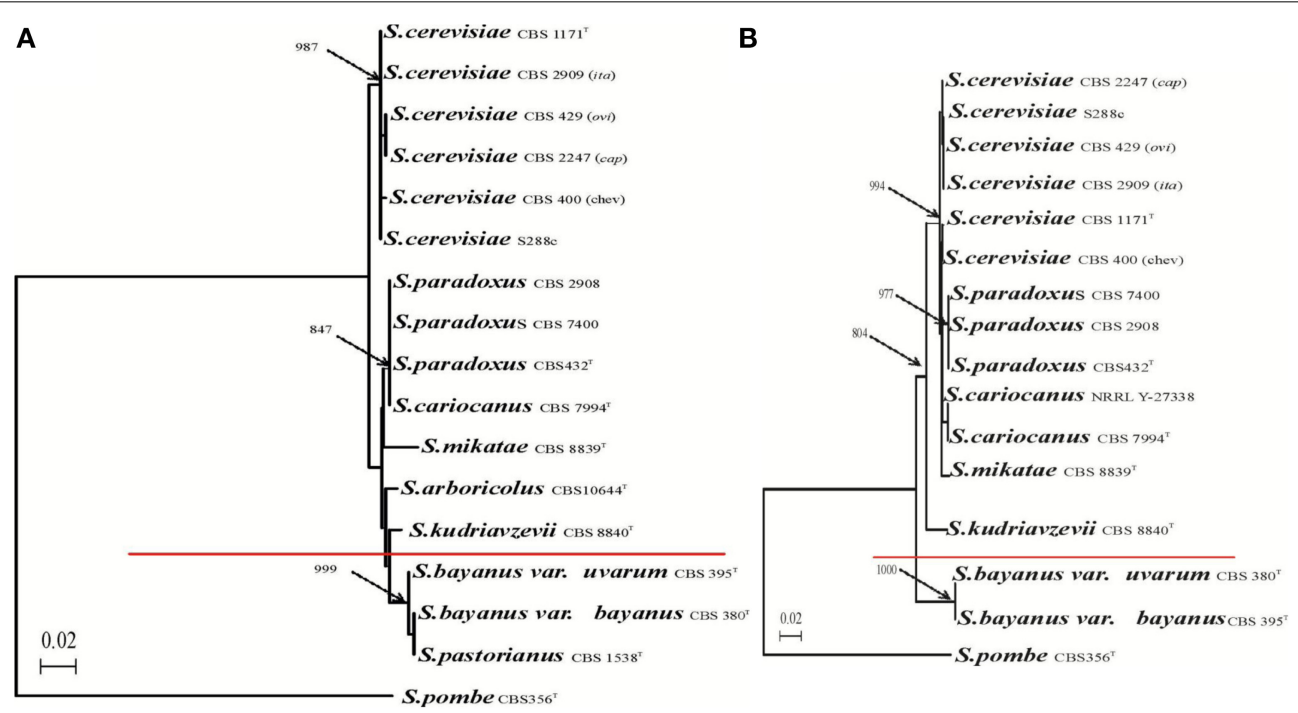

FIGURE 12 | Compatibility limit of $S$. cerevisiae nuclear genome and mitochondrial genomes from related yeasts. Phylogenetic tree of Saccharomyces species based on the comparison of (A) nuclear 26S rDNAs sequence and (B) mitochondrial cox2 gene. Branch lengths, based on nucleotide substitutions, are indicated by the bar. Bootstrap values of 1000 replications are marked by arrows at the branches points. Values less than $50 \%$ are not given. Schizosaccharomyces pombe was used as outgroup. 
corresponds to the human-rodents span and S. cerevisiae/S. bayanus to the human-birds distance. The limit confirms the transfer of S. cerevisiae mtDNA in the opposite direction. MtDNA containing all introns or intronless form is able to restore respiration in S. paradoxus, S. kudriavzevii and S. mikatae but not in $S$. bayanus to a level close to the original without adaptation period (unpublished). This emphasizes the unidirectional character of nucleo-mitochondrial incompatibilities and in particular the significant role of unusual $\operatorname{cox} 1-\mathrm{I} 3 \beta$ intron.

In conclusion, the interactions of $M R S 1-\operatorname{cox} 1$ considered as cytonuclear Dobzhansky-Muller pairs of speciation between S. cerevisiae and S. paradoxus are not strong enough to determine separation of species (Chou et al., 2010). Also, they do not play a dominant role in the separation between $S$. cerevisiae and the rest of the Saccharomyces species with the exception of species from the $S$. bayanus-S. uvarum clade (Figure 12). The compatibility is strain specific as the mitochondrial genomes can cooperate immediately and well-enough to support the utilization of nonfermentable substrate and sexual propagation. In the latter case, nuclear and mitochondrial genomes are capable of establishing collaborative communication after adaptation of one or several nuclear genes. Clear and strong cytonuclear incompatibility has been observed only between $S$. cerevisiae and S. bayanus, where additional Dobzhansky-Muller pairs have been reported (Chou et al., 2010).

Generally the post-zygotic barrier of speciation resulting in hybrid inviability and hybrid sterility has been attributed to a large number of genomic regions across a wide variety of species (for reviews Maheshwari and Barbash, 2011; Nosil and Schluter, 2011; Butlin et al., 2012; Mensch et al., 2013). In higher eukaryotes most of them involve chromosomal rearrangements and incompatibilities in nuclear Dobzhansky-Muller gene pairs (Maheshwari and Barbash, 2011). The yeasts with prevailing mito-nuclear incompatibilities are exception from this concept, although analogous mismatch have been found also in higher eukaryotes. MtDNA from chimpanzee, pigmy chimpanzee and gorilla but not from orangutan and less related primates is capable to restore oxidative phosphorylation in human cells devoid of mtDNA to essentially normal levels (Kenyon and Moraes, 1997; Barrientos et al., 1998). Similar relationships have been reported in mouse cybrids repopulated with mtDNA from various rodent species (Yamaoka et al., 2000; McKenzie et al., 2003, reviewed in Wolff et al., 2014). However, due to the uniparental inheritance of mitochondria, they are not considered as the main post-zygotic barrier. In yeast mitochondria are inherited biparentally that explains why cytonuclear incompatibility was preferentially observed in reproductive isolation (Lee et al., 2008; Chou et al., 2010). In addition, "yeast specific" combination of intron with species-specific splicing factor (such as incipient MRS1-cox1-I3 $\beta$ Dobzhansky-Muller pair) may play a significant role as post-zygotic barrier in other lower eukaryotes. Due to the horizontal transfer, mobile introns carrying homing endonuclease are able to "travel" between species in recurrent cycles of invasion, reading frame mutation and intron loss (Goddard and Burt, 1999). Homing endonucleases frequently possess maturase activity required for intron splicing. If their reading frame degenerates or is completely lost, proteins (like Mrsps) coded by nuclei and imported to mitochondria have to evolve rapidly to compensate the maturase activity loss. These splicing factors are often associated with several introns, what generates new and specific Dobzhansky-Muller pair with the potential to establish a new lineage. Introns considered as parasitic and selfish elements can thus serve as a triggers of speciation.

\section{ACKNOWLEDGMENTS}

This work was funded by grants from VEGA 1/3242/06, $1 / 0327 / 09$, and $1 / 0360 / 12$.

\section{REFERENCES}

Anderson, J. B., Funt, J., Thompson, D. A., Prabhu, S., Socha, A., Sirjusingh, C., et al. (2010). Determinants of divergent adaptation and Dobzhansky-Muller interaction in experimental yeast populations. Curr. Biol. 20, 1383-1388. doi: 10.1016/j.cub.2010.06.022

Anziano, P. Q., Moran, J. V., Gerber, D., and Perlman, P. S. (1990). Novel hybrid maturases in unstable pseudorevertants of maturaseless mutants of yeast mitochondrial DNA. Nucleic Acids Res. 18, 3233-3239. doi: 10.1093/nar/18. 11.3233

Arco, A. D., and Satrústegui, J. (2005). New mitochondrial carriers: an overview. Cell. Mol. Life Sci. 62, 2204-2227. doi: 10.1007/s00018-005-5197-x

Ausubel, F. M., Brent, R., Kingston, R. E., Moore, D. D., Seidman, J. G., Smith, J. A., et al. (2002). Current Protocols in Molecular Biology 1 and 2. New York, NY: Greene Publishing Associates; Wiley Interscience.

Barnett, J. A. (1992). The taxonomy of the genus Saccharomyces meyen ex reess: a short review for non-taxonomists. Yeast 8, 1-23. doi: 10.1002/yea.320080102

Barrientos, A., Kenyon, L., and Moraes, C. T. (1998). Human xenomitochondrial cybrids. Cellular models of mitochondrial complex I deficiency. J. Biol. Chem. 273, 14210-14217. doi: 10.1074/jbc.273.23.14210

Brown, T. (1993). "Analysis of RNA by northern and slot-blot hybridization," in Current Protocols in Molecular Biology, Vol. 1, Chapter 4.9.1, ed F. M. Ausubel (New York, NY: Greene Publishing Associates; Wiley Interscience), 2.10.1-2.10.16.

Burton, R. S., Pereira, R. J., and Barreto, F. S. (2013). Cytonuclear genomic interactions and hybrid breakdown. Annu. Rev. Ecol. Evol. Syst. 44, 281-302. doi: 10.1146/annurev-ecolsys-110512-135758

Butlin, R., Debelle, A., Kerth, C., Snook, R. R., Beukeboom, L. W., Castillo Cajas, R. F., et al. (2012). What do we need to know about speciation? Trends Ecol. Evol. 27, 27-39. doi: 10.1016/j.tree.2011.09.002

Charron, G., Leducq, J. B., and Landry, C. R. (2014). Chromosomal variation segregates within incipient species and correlates with reproductive isolation. Mol. Ecol. 23, 4362-4372. doi: 10.1111/mec.12864

Chou, J. Y., Hung, Y. S., Lin, K. H., Lee, H. Y., and Leu, J. Y. (2010). Multiple molecular mechanisms cause reproductive isolation between three yeast species. PLoS Biol. 8:e1000432. doi: 10.1371/journal.pbio.1000432

Chou, J. Y., and Leu, J. Y. (2010). Speciation through cytonuclear incompatibility: insights from yeast and implications for higher eukaryotes. Bioessays 32, 401-411. doi: 10.1002/bies.200900162

Defontaine, A., Lecocq, F. M., and Hallet, J. N. (1991). A rapid miniprep method for the preparation of yeast mitochondrial DNA. Nucleic Acids Res. 19, 185. doi: 10.1093/nar/19.1.185

Delneri, D., Colson, I., Grammenoudi, S., Roberts, I. N., Louis, E. J., and Oliver, S. G. (2003). Engineering evolution to study speciation in yeasts. Nature 422, 68-72. doi: 10.1038/nature01418

Dettman, J. R., Sirjusingh, C., Kohn, L. M., and Anderson, J. B. (2007). Incipient speciation by divergent adaptation and antagonistic epistasis in yeast. Nature 447, 585-588. doi: 10.1038/nature05856

Dey, R., Barrientos, A., and Moraes, C. T. (2000). Functional constraints of nuclearmitochondrial DNA interactions in xenomitochondrial rodent cell lines. J. Biol. Chem. 275, 31520-31527. doi: 10.1074/jbc.M004053200

Dihanich, M., Suda, K., and Schatz, G. (1987). A yeast mutant lacking mitochondrial porin is respiratory-deficient, but can recover respiration with simultaneous accumulation of an 86-kd extramitochondrial protein. Embo J. 6, 723-728.

Dimitrov, L. N., Brem, R. B., Kruglyak, L., and Gottschling, D. E. (2009). Polymorphisms in multiple genes contribute to the spontaneous mitochondrial 
genome instability of Saccharomyces cerevisiae S288C strains. Genetics 183, 365-383. doi: 10.1534/genetics.109.104497

Dobzhansky, T. G. (1937). Genetics and the Origin of Species. New York, NY: Columbia University Press.

Dujon, B. (2006). Yeasts illustrate the molecular mechanisms of eukaryotic genome evolution. Trends Genet. 22, 375-387. doi: 10.1016/j.tig.2006.05.007

Eide, D. J., Clark, S., Nair, T. M., Gehl, M., Gribskov, M., Guerinot, M. L., et al. (2005). Characterization of the yeast ionome: a genome-wide analysis of nutrient mineral and trace element homeostasis in Saccharomyces cerevisiae. Genome Biol. 6:R77. doi: 10.1186/gb-2005-6-9-r77

Foury, F., and Roganti, T. (2002). Deletion of the mitochondrial carrier genes MRS3 and MRS4 suppresses mitochondrial iron accumulation in a yeast frataxindeficient strain. J. Biol. Chem. 277, 24475-24483. doi: 10.1074/jbc.M111 789200

Foury, F., Roganti, T., Lecrenier, N., and Purnelle, B. (1998). The complete sequence of the mitochondrial genome of Saccharomyces cerevisiae. FEBS Lett 440, 325-331. doi: 10.1016/S0014-5793(98)01467-7

Fox, T. D. (2012). Mitochondrial protein synthesis, import, and assembly. Genetics 192, 1203-1234. doi: 10.1534/genetics.112.141267

Fox, T. D., Folley, L. S., Mulero, J. J., McMullin, T. W., Thorsness, P. E., Hedin, L. O., et al. (1991). "Analysis and manipulation of yeast mitochondrial genes," in Methods in Enzymology: Vol. 194, Guide to Yeast Genetics and Molecular Biology, eds C. Guthrie and G. R. Fink (San Diego, CA: Academic Press), 149-165.

Goddard, M. R., and Burt, A. (1999). Recurrent invasion and extinction of a selfish gene. Proc. Natl. Acad. Sci. U.S.A. 96, 13880-13885. doi: 10.1073/pnas.96.24.13880

Greig, D. (2007). A screen for recessive speciation genes expressed in the gametes of F1 hybrid yeast. PLoS Genet. 3:e21. doi: 10.1371/journal.pgen.0030021

Greig, D. (2009). Reproductive isolation in Saccharomyces. Heredity 102, 39-44. doi: 10.1038/hdy.2008.73

Greig, D., Louis, E. J., Borts, R. H., and Travisano, M. (2002). Hybrid speciation in experimental populations of yeast. Science 298, 1773-1775. doi: 10.1126/science. 1076374

Guthrie, C., and Fink, G. R. (1991). Methods in Enzymology: Vol. 194, Guide to Yeast Genetics and Molecular Biology. San Diego, CA: Academic Press.

Hampsey, M. (1997). A review of phenotypes in Saccharomyces cerevisiae. Yeast 13, 1099-1133.

Herbert, C. J., Macadre, C., Bécam, A. M., Lazowska, J., and Slonimski, P. P. (1992). The MRSI gene of $S$. douglasii: co-evolution of mitochondrial introns and specific splicing proteins encoded by nuclear genes. Gene Expr. 2, 203-214.

Hittinger, C. T. (2013). Saccharomyces diversity and evolution: a budding model genus. Trends Genet. 29, 309-317. doi: 10.1016/j.tig.2013.01.002

Hou, J., Friedrich, A., de Montigny, J., and Schacherer, J. (2014). Chromosomal rearrangements as a major mechanism in the onset of reproductive isolation in Saccharomyces cerevisiae. Curr. Biol. 24, 1153-1159. doi 10.1016/j.cub.2014.03.063

Hunter, N., Chambers, S. R., Louis, E. J., and Borts, R. H. (1996). The mismatch repair system contributes to meiotic sterility in an interspecific yeast hybrid. Embo J. 15, 1726-1733.

Kao, K. C., Schwartz, K., and Sherlock, G. (2010). A genome-wide analysis reveals no nuclear Dobzhansky-Muller pairs of determinants of speciation between S. cerevisiae and S. paradoxus, but suggests more complex incompatibilities. PLoS Genet. 6:e1001038. doi: 10.1371/journal.pgen.1001038

Kao, L. R., Megraw, T. L., and Chae, C. B. (1993). Essential role of the HMG domain in the function of yeast mitochondrial histone HM: functional complementation of HM by the nuclear nonhistone protein NHP6A. Proc. Natl. Acad. Sci. U.S.A. 90, 5598-5602. doi: 10.1073/pnas.90.12.5598

Kenyon, L, and Moraes, C. T. (1997). Expanding the functional human mitochondrial DNA database by the establishment of primate xenomitochondrial cybrids. Proc. Natl Acad. Sci. U.S.A. 94, 9131-9135. doi: 10.1073/pnas.94. 17.9131

Köhrer, K., and Domdey, H. (1991). "Preparation of high molecular weight RNA," in Methods in Enzymology: Vol. 194, Guide to Yeast Genetics and Molecular Biology, eds C. Guthrie and G. R. Fink (San Diego, CA: Academic Press), 398-405.

Kolisek, M., Zsurka, G., Samaj, J., Weghuber, J., Schweyen, R. J., and Schweigel, M. (2003). Mrs2p is an essential component of the major electrophoretic $\mathrm{Mg}^{2+}$ influx system in mitochondria. Embo J. 22, 1235-1244. doi: 10.1093/emboj/cdg122
Koll, H., Schmidt, C., Wiesenberger, G., and Schmelzer, C. (1987). Three nuclear genes suppress a yeast mitochondrial splice defect when present in high copy number. Curr. Genet. 12, 503-509. doi: 10.1007/BF00419559

Kotylak, Z., Lazowska, J., and Slonimski, P. P. (1985). "Intron encoded proteins of mitochondria: key elements of gene expression and genomic evolution," in Achievements and Perspectives of Mitochondrial Research: Vol. II, Biogenesis, ed E. Quagliariello (Amsterdam, NL: Elsevier), 1-20.

Kurtzman, C. P. (2003). Phylogenetic circumscription of Saccharomyces, Kluyveromyces and other members of the Saccharomycetaceae, and the proposal of the new genera Lachancea, Nakaseomyces, Naumonia, Vanderwaltozyma and Zygotoruspora. FEMS Yeast Res. 4, 233-245. doi: 10.1016/S1567-1356(03) 00175-2

Kurtzman, C. P., and Robnett, C. J. (2003). Phylogenetic relationships among yeasts of the 'Saccharomyces complex' determined from multigene sequence analyses. FEMS Yeast Res. 3, 417-432. doi: 10.1016/S1567-1356(03)00012-6

Lee, H. Y., Chou, J. Y., Cheong, L., Chang, N. H., Yang, S. Y., and Leu, J. Y. (2008). Incompatibility of nuclear and mitochondrial genomes causes hybrid sterility between two yeast species. Cell 135, 1065-1073. doi: 10.1016/j.cell.2008.10.047

Levra-Juillet, E., Boulet, A., Seraphin, B., Simon, M., and Faye, G. (1989). Mitochondrial introns aI1 and/or aI2 are needed for the in vivo deletion of intervening sequences. Mol. Gen. Genet. 217, 168-171. doi: 10.1007/BF003 30957

Lin, Y. S., Byrnes, J. K., Hwang, J. K., and Li, W. H. (2006). Codon-usage bias versus gene conversion in the evolution of yeast duplicate genes. Proc. Natl. Acad. Sci. U.S.A. 103, 14412-14416. doi: 10.1073/pnas.0606348103

Lipinski, K. A., Kaniak-Golik, A., and Golik, P. (2010). Maintenance and expression of the $S$. cerevisiae mitochondrial genome-from genetics to evolution and systems biology. Biochim. Biophys. Acta 1797, 1086-1098. doi: 10.1016/j.bbabio.2009.12.019

Liti, G., Barton, D. B., and Louis, E. J. (2006). Sequence diversity, reproductive isolation and species concepts in Saccharomyces. Genetics 174, 839-850. doi: 10.1534/genetics.106.062166

Louis, E. J. (2011). Population genomics and speciation in yeasts. Fungal Biol. Rev. 25, 136-142. doi: 10.1016/j.fbr.2011.06.001

Maheshwari, S., and Barbash, D. A. (2011). The genetics of hybrid incompatibilities. Annu. Rev. Genet. 45, 331-355. doi: 10.1146/annurev-genet-110410132514

Marinoni, G., Manuel, M., Petersen, R. F., Hvidtfeldt, J., Sulo, P., and Piskur, J. (1999). Horizontal transfer of genetic material among Saccharomyces yeasts. J. Bacteriol. 181, 6488-6496.

McKenzie, M., and Trounce, I. (2000). Expression of Rattus norvegicus mtDNA in Mus musculus cells results in multiple respiratory chain defects. J. Biol. Chem. 275, 31514-31519. doi: 10.1074/jbc.M004070200

McKenzie, M., Chiotis, M., Pinkert, C. A., and Trounce I. A. (2003). Functional respiratory chain analyses in murid xenomitochondrial cybrids expose coevolutionary constraints of cytochrome b and nuclear subunits of complex III. Mol. Biol. Evol. 20, 1117-1124. doi: 10.1093/molbev/msg132

Mensch, J., Frankel, N., and Hasson, E. (2013). Speciation Genes. eLS. Chichester: John Wiley and Sons, Ltd.

Morales, L., and Dujon, B. (2012). Evolutionary role of interspecies hybridization and genetic exchanges in yeasts. Microbiol. Mol. Biol. Rev. 76, 721-739. doi: 10.1128/MMBR.00022-12

Mühlenhoff, U., Gerber, J., Richhardt, N., and Lill, R. (2003). Components involved in assembly and dislocation of iron-sulfur clusters on the scaffold protein Isulp. Embo J. 22, 4815-4825. doi: 10.1093/emboj/cdg446

Naumov, G. I., James, S. A., Naumova, E. S., Louis, E. J., and Roberts, I. N. (2000). Three new species in the Saccharomyces sensu stricto complex: Saccharomyces cariocanus, Saccharomyces kudriavzevii and Saccharomyces mikatae. Int. J. Syst. Evol. Microbiol. 50, 1931-1942. doi: 10.1099/00207713-50-5-1931

Nilsson-Tillgren, T., Petersen, J. G. L., Holmberg, S., and Kielland-Brandt, M. C. (1980). Transfer of chromosome III during Kar mediated cytoduction in yeast. Carlsberg Res. Commun. 45, 113-117. doi: 10.1007/BF02906512

Nosil, P., and Schluter, D. (2011). The genes underlying the process of speciation. Trends Ecol. Evol. 26, 160-167. doi: 10.1016/j.tree.2011.01.001

Osusky, M., Kissova, J., and Kovac, L. (1997). Interspecies transplacement of mitochondria in yeasts. Curr. Genet. 32, 24-26. doi: 10.1007/s002940 050243

Oxelmark, E., Marchini, A., Malanchi, I., Magherini, F., Jaquet, L., Hajibagheri, M. A., et al. (2000). Mmflp, a novel yeast mitochondria 
protein conserved throughout evolution and involved in maintenance of the mitochondrial genome. Mol. Cell. Biol. 20, 7784-7797. doi: 10.1128/MCB.20.20.7784-7797.2000

Paliwal, S., Fiumera, A. C., and Fiumera, H. L. (2014). Mitochondrial-nuclear epistasis contributes to phenotypic variation and coadaptation in natural isolates of Saccharomyces cerevisiae. Genetics. 198, 1251-1265. doi: 10.1534/genetics. 114.168575

Pandit, S., Paul, S., Zhang, L., Chen, M., Durbin, N., Harrison, S. M., et al. (2009). Spp382p interacts with multiple yeast splicing factors, including possible regulators of Prp43 DExD/H-Box protein function. Genetics 183, 195-206. doi: 10.1534/genetics.109.106955

Partaledis, J. A., and Mason, T. L. (1988). Structure and regulation of a nuclear gene in Saccharomyces cerevisiae that specifies MRP13, a protein of the small subunit of the mitochondrial ribosome. Mol. Cell. Biol. 8, 3647-3660.

Philippsen, P., Stotz, A., and Scherf, C. (1991). DNA of Saccharomyces cerevisiae, in Methods in Enzymology: Vol. 194, Guide to Yeast Genetics and Molecular Biology, eds C. Guthrie and G. R. Fink (San Diego, CA: Academic Press), 169-182.

Prochazka, E., Franko, F., Poláková, S., and Sulo, P. (2012). A complete sequence of Saccharomyces paradoxus mitochondrial genome that restores the respiration in S. cerevisiae. FEMS Yeast Res. 12, 819-830. doi: 10.1111/j.15671364.2012.00833.x

Querol, A., Barrio, E., and Ramon, D. (1992). A comparative study of different methods of yeast strain characterization. Syst. Appl. Microbiol. 15, 439-446. doi: 10.1016/S0723-2020(11)80219-5

Rainieri, S., Kodama, Y., Nakao, Y., Pulvirenti, A., and Giudici, P. (2008). The inheritance of mtDNA in lager brewing strains. FEMS Yeast Res. 8, 586-596. doi: 10.1111/j.1567-1364.2008.00363.x

Ramer, S. W., Elledge, S. J., and Davis, R. W. (1992). Dominant genetics using a yeast genomic library under the control of a strong inducible promoter. Proc. Natl. Acad. Sci. U.S.A. 89, 11589-11593. doi: 10.1073/pnas.89.23.11589

Rose, M. D., and Broach, J. R. (1991). "Cloning genes by complementation in yeast," in Methods in Enzymology: Vol. 194, Guide to Yeast Genetics and Molecular Biology, eds C. Guthrie and G. R. Fink (San Diego, CA: Academic Press), 195-230.

Sakanaka, K., Yan, W., Kishida, M., and Sakai, T. (1996). Introduction of mitochondria into respiratory-deficient mutant of yeast and improvement of thermostability. J. Ferment. Bioeng. 81, 109-114. doi: 10.1016/0922-338X(96)87586-6

Scannell, D. R., Zill, O. A., Rokas, A., Payen, C., Dunham, M. J., Eisen, M. B., et al. (2011). The awesome power of yeast evolutionary genetics: new genome sequences and strain resources for the Saccharomyces sensu stricto genus. G3 (Bethesda) 1, 11-25. doi: 10.1534/g3.111.000273

Schmidt, O., Pfanner, N., and Meisinger, C. (2010). Mitochondrial protein import: from proteomics to functional mechanisms. Nat. Rev. Mol. Cell Biol. 11, 655-667. doi: 10.1038/nrm2959

Seraphin, B., Boulet, A., Simon, M., and Faye, G. (1987). Construction of a yeast strain devoid of mitochondrial introns and its use to screen nuclear genes involved in mitochondrial splicing. Proc. Natl. Acad. Sci. U.S.A. 84, 6810-6814. doi: 10.1073/pnas.84.19.6810

Sikorski, R. S., and Boeke, J. D. (1991). "In vitro mutagenesis and plasmid shuffling: from cloned gene to mutant yeast," in Methods in Enzymology: Vol. 194, Guide to Yeast Genetics and Molecular Biology, eds C. Guthrie and G. R. Fink (San Diego, CA: Academic Press), 302-318.

Solieri, L. (2010). Mitochondrial inheritance in budding yeasts: towards an integrated understanding. Trends Microbiol. 18, 521-530. doi 10.1016/j.tim.2010.08.001

Solieri, L., Antunez, O., Perez-Ortin, J. E., Barrio, E., and Giudici, P. (2008). Mitochondrial inheritance and fermentative: oxidative balance in hybrids between Saccharomyces cerevisiae and Saccharomyces uvarum. Yeast 25, 485-500. doi: 10.1002/yea. 1600

Soni, R., Carmichael, J. P., and Murray, J. A. (1993). Parameters affecting lithium acetate-mediated transformation of Saccharomyces cerevisiae and development of a rapid and simplified procedure. Curr. Genet. 24, 455-459. doi: 10.1007/BF00351857

Špírek, M., Horvath, A., Piskur, J., and Sulo, P. (2000). Functional co-operation between the nuclei of Saccharomyces cerevisiae and mitochondria from other yeast species. Curr. Genet. 38, 202-207. doi: 10.1007/s002940000155

Špírek, M., Soltesova, A., Horvath, A., Slavikova, E., and Sulo, P. (2002). GC clusters and the stability of mitochondrial genomes of Saccharomyces cerevisiae and related yeats. Folia Microbiol. 47, 263-270. doi: 10.1007/BF02817649
Sulo, P., Griac, P., Klobucníkova, V., and Kovac, L. (1989). A method for the efficient transfer of isolated mitochondria into yeast protoplasts. Curr. Genet. 15, 1-6. doi: 10.1007/BF00445745

Sulo, P., Špírek, M., Soltesova, A., Marinoni, G., and Piskur, J. (2003). The efficiency of functional mitochondrial replacement in Saccharomyces species has directional character. FEMS Yeast Res. 4, 97-104. doi: 10.1016/S1567-1356(03) 00109-0

Teng, X., Dayhoff-Brannigan, M., Cheng, W. C., Gilbert, C. E., Sing, C. N., Diny, N. L., et al. (2013). Genome-wide consequences of deleting any single gene. Mol. Cell. 52, 485-494. doi: 10.1016/j.molcel.2013.09.026

Tian, G. L., Michel, F., Macadre, C., and Lazowska, J. (1993). Sequence of the mitochondrial gene encoding subunit I of cytochrome oxidase in Saccharomyces douglasii. Gene 124, 153-163. doi: 10.1016/0378-1119(93)90389-K

Traven, A., Wong, J. M., Xu, D., Sopta, M., and Ingles, C. J. (2001). Interorganellar communication. Altered nuclear gene expression profiles in a yeast mitochondrial DNA mutant. J. Biol. Chem. 276, 4020-4027. doi: 10.1074/jbc.M0068 07200

Tzagoloff, A., Akai, A., and Needleman, R. B. (1975). Assembly of the mitochondrial membrane system. Characterization of nuclear mutants of Saccharomyces cerevisiae with defects in mitochondrial ATPase and respiratory enzymes. J. Biol. Chem. 250, 8228-8235.

Vaughan-Martini, A., and Martini, A. (2011). "Saccharomyces meyen ex reess (1870)," in The Yeasts, A Taxonomic Study, ed C. P. Kurtzman (Amsterdam, NL: Elsevier), 733-746.

Waldherr, M., Ragnini, A., Jank, B., Teply, R., Wiesenberger, G, and Schweyen, R., J. (1993). A multitude of suppressors of group II intron-splicing defects in yeast. Curr. Genet. 24, 301-306. doi: 10.1007/BF00336780

Watts, T., Khalimonchuk, O., Wolf, R. Z., Turk, E. M., Mohr, G., and Winge, D. R. (2011). Mnel is a novel component of the mitochondrial splicing apparatus responsible for processing of a COX1 group I intron in yeast. J. Biol. Chem. 286, 10137-10146. doi: 10.1074/jbc.M110.205625

Wiesenberger, G., Link, T. A., von Ahsen, U., Waldherr, M., and Schweyen, R. J. (1991). MRS3 and MRS4, two suppressors of mtRNA splicing defects in yeast, are new members of the mitochondrial carrier family. J. Mol. Biol. 217, 23-37. doi: 10.1016/0022-2836(91)90608-9

Wiesenberger, G., Waldherr, M., and Schweyen, R. J. (1992). The nuclear gene MRS2 is essential for the excision of group II introns from yeast mitochondrial transcripts in vivo. J. Biol. Chem. 267, 6963-6969.

Wolff, J. N., Ladoukakis, E. D., Enriquez, J. A., and Dowling, D. K. (2014). Mitonuclear interactions: evolutionary consequences over multiple biological scales. Philos. Trans. R. Soc. Lond. B Biol. Sci. 369:20130443. doi: 10.1098/rstb.2013.0443

Yamaoka, M., Isobe, K., Shitara, H., Yonekawa, H., Miyabayashi, S., and Hayashi, J. I. (2000). Complete repopulation of mouse mitochondrial DNA-less cells with rat mitochondrial DNA restores mitochondrial translation but not mitochondrial respiratory function. Genetics 155, 301-307.

Yoshida, K. (1979). Interspecific and intraspecific mitochondria-induced cytoplasmic transformation in yeasts. Plant Cell Physiol. 20, 851-856.

Zeyl, C., Andreson, B., and Weninck, E. (2005). Nuclear-mitochondrial epistasis for fitness in Saccharomyces cerevisiae. Evolution 59, 910-914. doi: 10.1111/j.00143820.2005.tb01764.x

Conflict of Interest Statement: The authors declare that the research was conducted in the absence of any commercial or financial relationships that could be construed as a potential conflict of interest.

Received: 28 October 2014; accepted: 11 December 2014; published online: 12 January 2015.

Citation: Špírek M, Poláková S, Jatzová K and Sulo P (2015) Post-zygotic sterility and cytonuclear compatibility limits in S. cerevisiae xenomitochondrial cybrids. Front. Genet. 5:454. doi: 10.3389/fgene.2014.00454

This article was submitted to Evolutionary and Population Genetics, a section of the journal Frontiers in Genetics.

Copyright (C) 2015 Špirek, Poláková, Jatzová and Sulo. This is an open-access article distributed under the terms of the Creative Commons Attribution License (CC BY). The use, distribution or reproduction in other forums is permitted, provided the original author(s) or licensor are credited and that the original publication in this journal is cited, in accordance with accepted academic practice. No use, distribution or reproduction is permitted which does not comply with these terms. 